\title{
Bolzano's Concept of Grounding (Abfolge) against the Background of Normal Proofs
}

\author{
Antje Rumberg*
}

Final Draft: April 2013

\begin{abstract}
In this paper I will provide a thorough discussion and reconstruction of Bernard Bolzano's theory of grounding and a detailed investigation into the parallels between his concept of grounding and current notions of normal proofs. Grounding (Abfolge) is an objective ground-consequence relation among true propositions that is explanatory in nature. The grounding relation plays a crucial role in Bolzano's proof-theory, and it is essential for his views on the ideal buildup of scientific theories. Occasionally, similarities have been pointed out between Bolzano's ideas on grounding and cut-free proofs in Gentzen's sequent calculus. My thesis is, however, that they bear an even stronger resemblance to the normal natural deduction proofs employed in proof-theoretic semantics in the tradition of Dummett and Prawitz.
\end{abstract}

\section{Introduction}

In his Wissenschaftslehre ${ }^{1}$ (henceforth: WL) the philosopher and mathematician Bernard Bolzano sets forth to provide 'a Detailed and in the main Novel Exposition of Logic'.2 Bolzano conceives of logic as a 'theory of science' and ascribes to logic the task of providing rules for arranging the sciences and their presentations in textbooks (WL, $\S 15$ [I.56]). In this context his grounding relation is of pivotal importance. Grounding (Abfolge $)^{3}$ is an objective ground-consequence relation among true

\footnotetext{
${ }^{*}$ Department of Philosophy, Utrecht University, The Netherlands, Antje.Rumberg@phil.uu.nl

${ }^{1}$ Bolzano, B. (1837). Dr. B. Bolzanos Wissenschaftslehre: Versuch einer ausführlichen und größtentheils neuen Darstellung der Logik mit stetiger Rücksicht auf deren bisherige Beareiter. Bände 1-4. Sulzbach: Seidelsche Buchhandlung. English translation by Paul Rusnock and Rolf George. Unpublished. I am thankful to Paul Rusnock for making accessible to me the English translation. Citations refer to the German original edition and take the following form: WL, paragraph [volume.page]. When quoting Bolzano, I provide the original German text as a footnote.

${ }^{2}$ Cf. subtitle of WL.

${ }^{3}$ Bolzano's term Abfolge has sometimes been translated as 'entailment', 'consequence', 'the relation of ground and consequence' or 'the ground-consequence relation'. In the recent literature on Bolzano's concept of Abfolge, it has become common to translate the term as 'grounding' (cf. Betti (2010), Betti (2012), Lapointe (2011), Sebestik (2012), Tatzel (2001), Tatzel (2002), Schnieder (2013)), and I have decided to follow this practice. In doing so, I am deviating from the translation by Paul Rusnock and Rolf George, which I otherwise use throughout the paper, where Abfolge is translated as 'the relation of ground and consequence'. Apart from respecting practice within current literature on Bolzano, translating Abfolge as 'grounding' enhances expressibility: the term
} 
propositions that is explanatory in nature. It is an ontological relation in the ordo essendi that obtains independently of our knowledge. At the same time, the grounding relation figures prominently in the context of proofs, which serve an epistemic purpose and belong to the ordo cognoscendi. It plays a crucial role in Bolzano's proof-theory, and it is essential for his views on the ideal buildup of scientific theories. According to Bolzano's ideal, scientific theories are organized in axiomatic hierarchies ordered via the grounding relation, i.e., the theorems are not only provable from the axioms, but are at the same time grounded in them. ${ }^{4}$

Taking up a distinction that can already be found in Aristotle ${ }^{5}$, Bolzano distinguishes between two kinds of proofs: proofs which merely show that the conclusion is true and proofs which also show why it is true (WL, $\S 525$ [IV.261]). According to Bolzano, a proof in which the conclusion is derived from true premises via intermediate grounding steps constitutes an explanatory proof (Begründung). It does not only establish the truth of its conclusion, but also reveals its grounds. Since proofs based on the grounding relation take the form of a tree, I will call them - or rather what corresponds to them in Bolzano's propositional realm - grounding trees.

Bolzano's theory of grounding, which has only rarely been dealt with in the literature for a long time, is nowadays receiving increasing attention. ${ }^{6}$ The aim of this paper is to discuss Bolzano's theory of grounding against the background of normal proofs, which will shed light on the general idea underlying the concept of grounding as a proof-theoretic notion. Occasionally, parallels have been pointed out between Bolzano's ideas on grounding and Gerhard Gentzen's cut-free proofs in the sequent calculus. The most elaborate discussion is Tatzel (2001). My thesis is, however, that Bolzano's grounding trees bear an even stronger resemblance to the normal natural deduction proofs employed in proof-theoretic semantics in the tradition of Michael Dummett and Dag Prawitz. In proof-theoretic semantics, natural deduction proofs in which the conclusion is derived from its atomic subformulas (governed by an atomic base) by the mere application of introduction rules are taken to display the meaning of complex sentences in terms of their assertibility conditions.

In this paper I will provide a thorough discussion and reconstruction of Bolzano's theory of grounding and a detailed investigation into the parallels between his concept of grounding and current notions of normal proofs. The first part of the paper is devoted to Bolzano's concept of grounding. I will discuss the peculiar properties of grounding, thereby distinguishing between different variants of the grounding relation: immediate and mediate, complete and partial ones. In the second part of the paper, I will compare Bolzano's concept of grounding to current notions of normal proofs. I

'grounding' comes with a verb form, viz. 'to ground', and facilitates reference to the different variants of the grounding relation, which I call 'complete (immediate) grounding' and 'partial (immediate) grounding'. Although Bolzano's concept of Abfolge bears quite some similarities to what is discussed in recent metaphysics under the heading of grounding (cf. Correira and Schnieder (2012), e.g. Fine (2012) included in that collection), it should not without further argument be taken to coincide with the notion of grounding in those metaphysical debates, despite the use of the same terminology.

${ }^{4}$ Cf. WL, §525. For a discussion of Bolzano's views on the ideal buildup of scientific theories, see Betti (2010), ch.2; Buhl (1961), 53 ff.

${ }^{5}$ Aristotle, Posterior Analytics I.13. Bolzano explicitly refers to Aristotle himself (WL, §198 [II.341]).

${ }^{6}$ Consider, for instance, Betti (2010), Betti (2012), Centrone (2011), Centrone (2012), Mancosu (1999), Schnieder (2011), Schnieder (2013), Sebestik (2012), Sundholm (2009), Sundholm (2011), Tatzel (2001), Tatzel (2002). 
will briefly address the similarities between Bolzano's ideas on grounding and cut-free proofs in Gentzen's sequent calculus, and then provide a detailed investigation into the parallels between Bolzano's grounding trees and the normal natural deduction proofs considered by Dummett and Prawitz in the context of proof-theoretic semantics. Before I will discuss Bolzano's concept of grounding, however, a few remarks on the basic concepts of Bolzano's philosophy and logic are in order.

\section{The basic concepts of Bolzano's philosophy and logic}

The most fundamental concept of Bolzano's philosophy and logic is that of a proposition in itself (in short: proposition; Satz an sich). Propositions in the Bolzanian sense are abstract (i.e. non-spatio-temporal), mind-independent entities. They serve as contents of our judgements and as the meaning of the sentences of a language and constitute the subject of logic (cf. WL, $\S \S 16,19,122)$. Bolzano explains:

[B]y proposition in itself I mean any assertion [Aussage] that something is or is not the case, regardless whether or not somebody has put it into words, and regardless even whether or not it has been thought. ${ }^{7}$ (WL, $\S 19$ [I.77])

Propositions are the primary bearers of truth and falsity and are either true or false (WL, §125). They have an objective truth value that is fixed once and for all. Moreover, propositions are complex, structured entities (WL, §123). Their nonpropositional parts, i.e. 'anything that can be part of a proposition in itself, without being itself a proposition', are called ideas in themselves (in short: ideas; Vorstellungen an sich) (WL, §48 [I.216]). Ideas can represent, or fail to represent, objects as well as properties (WL, $\S \S 49,66$ ) and are either simple or complex (WL, $\S \S 56,58,61$ ). Simple ideas are the ultimate constituents of complex ideas and propositions. They are not further decomposable. Complex ideas and propositions are built up from occurrences of simple ideas.

On first analysis, every Bolzanian proposition - even a complex one - consists of a subject idea and a predicate idea connected by the simple idea [has] and has the underlying form ' $A$ has $b$ ' (WL, $\S 81$ [I.393], $\S \S 126,127){ }^{8}$ On final analysis, every proposition can be decomposed into occurrences of simple ideas as its ultimate parts. I will call the collection ${ }^{9}$ of all occurrences of simple ideas from which a given proposition $\phi$ is built up its simple content and denote it by ' $C_{\phi} \cdot{ }^{10}$ If a simple idea occurs more

\footnotetext{
${ }^{7}[\mathrm{U}]$ nter einem Satz an sich verstehe ich nur irgend eine Aussage, daß etwas ist oder nicht ist; gleichviel, ob diese Aussage wahr oder falsch ist; ob sie von irgend Jemand in Worte gefaßt, ja auch im Geiste nur gedacht oder nicht gedacht worden ist.

${ }^{8} \mathrm{As}$ it is common in the Bolzano literature, the result of enclosing a term or a sentence in square brackets will be used to denote the idea or proposition, respectively, expressed by that term or sentence.

${ }^{9}$ The concept of a collection is a mereological notion. Roughly speaking, a collection is something which has parts (WL, $\S \S 82-84$ ). For a discussion of Bolzano's mereology, see Betti (2012), ch.4. For matters of convenience, I will use set-theoretic notation here and allow for collections consisting of just one element. For a comparison between collections and sets, see Siebel (1996), 36-45.

${ }^{10}$ Bolzano defines the content (Inhalt) of a proposition as 'the sum [Summe] of all its immediate and remote parts' (WL, $\S 123$ [II.5]). Apart from the propositional form ' $A$ has $b$ ', we do unfortunately not know much about the general buildup of Bolzano's propositions. All that Bolzano provides are some modes of propositional composition (cf. WL, §135).
} 
than once in a given proposition $\phi$ (cf. WL, $\S 174$ [III.16]), its simple content $C_{\phi}$ contains multiple copies of it. The simple content thus measures the complexity of a proposition. In modern terms the simple content of a proposition is perhaps best thought of as a multi set. ${ }^{11}$ A proposition is defined true, and accordingly called a truth in itself (in short: truth; Wahrheit an sich), just in case the subject idea represents at least one object, and every object falling under it has at least one of the properties represented by the predicate idea (WL, $\S \S 25,127,196)$.

Next to the grounding relation, with which we are concerned here, Bolzano provides yet another consequence relation called deducibility (Ableitbarkeit) ${ }^{12}$, which is frequently considered as an ancestor of Alfred Tarski's notion of logical consequence. ${ }^{13}$ Bolzano's definition of deducibility is based on his method of variation, which consists in the uniform substitution of an explicitly given collection of non-logical ideas by some other suitable collection of ideas within a given collection of propositions. ${ }^{14}$ Let $\Gamma$ and $\Delta$ range over non-empty collections of propositions, and let $v$ and $w$ range over non-empty collections of ideas. The variant $\Gamma\left(w_{1} / v_{1}, \ldots, w_{n} / v_{n}\right)$, which results from substituting a collection of ideas $w=\left\{w_{1}, \ldots, w_{n}\right\}$ for a collection of ideas $v=\left\{v_{1}, \ldots, v_{n}\right\}$ in every proposition contained within the collection $\Gamma$, will shortly be written $\Gamma(w / v)$. A collection of propositions is said to be true if all of its parts are. Deducibility is defined in terms of truth preservation from a collection of premises to a collection of conclusions under any admissible variation of an explicitly given collection of variable ideas. Bolzano writes:

[I] say that propositions $M, N, O, \ldots$ are deducible from propositions $A, B$, $C, D, \ldots$ with respect to variable parts $i, j, \ldots$ if every collection of ideas whose substitution for $i, j, \ldots$ makes all of $A, B, C, D, \ldots$ true, also makes all of $M, N, O, \ldots$ true. $^{15}$ (WL, $\S 155$ [II.114])

It is important to note that Bolzano takes it to be a necessary condition for deducibility that the premises be compatible with respect to the collection of variable ideas $v$ (verträglich; WL II, §154), i.e., there must be at least one collection $w$ such

\footnotetext{
${ }^{11}$ For a discussion of what it means for an idea as an abstract object to have multiple occurrences within a proposition, see Künne (1997), 223-226. Künne refers to this question as 'the repetition problem'.

${ }^{12}$ Bolzano's term Ableitbarkeit is sometimes translated as 'deducibility' and sometimes as 'derivability'. In recent years, 'deducibility' has become more and more frequent. This is the terminology found in the translation by Paul Rusnock and Rolf George, and it is suggested as standard translation in the English edition of Bolzano (1981). The problem with either of those translations is that, while Bolzano's concept of Ableitbarkeit corresponds to the notion of semantic consequence, the expressions 'deducibility' and 'derivability' are typically taken to refer to a syntactic notion defined in terms of formal derivations in a given calculus.

${ }^{13}$ Cf. Tarski (1936). In the English translation Tarski himself admits 'a far-reaching analogy' between his definition of logical consequence and Bolzano's definition of deducibility (cf. Tarski (1956), 417), after the similarity between the two notions has been pointed out to him by Scholz (cf. Scholz (1937), 470 ff.). For an elaborate discussion of Bolzano's concept of deducibility and its parallels to Tarski's notion of logical consequence, see Siebel (1996), Siebel (2002), Rusnock and Burke (2010).

${ }^{14}$ For a discussion of Bolzano's method of variation, see Morscher (2013), ch.3.6.

${ }^{15}$ Ich [...] sage daß die Sätze $M, N, O, \ldots$ ableitbar wären aus den Sätzen $A, B, C, D, \ldots$ hinsichtlich auf die veränderlichen Theile $i, j, \ldots$, wenn jeder Inbegriff von Vorstellungen, der an der Stelle der $i, j, \ldots$ die sämmtlichen $A, B, C, D, \ldots$ wahr macht, auch die gesammten $M, N, O, \ldots$ wahr macht.
} 
that substituting $w$ for $v$ results in a true variant of the premises. With the above terminology at hand, we can restate Bolzano's definition of deducibility as follows:

(D) $\Delta$ is deducible from $\Gamma$ with respect to $v\left(\Gamma \vDash_{v} \Delta\right)$ iff

(i) there is some $w$ such that $\Gamma(w / v)$ is true; and

(ii) for all $w$ : if $\Gamma(w / v)$ is true, then $\Delta(w / v)$ is true.

Although Bolzano's concept of deducibility and Tarski's notion of logical consequence have the same underlying idea, there are also crucial differences between the two definitions. Apart from the fact that Bolzano defines deducibility as holding between collections of abstract propositions rather than sentences, makes use of substitution rather than reinterpretation or satisfaction, allows for multiple conclusions and requires that the premises be compatible, Bolzano's definition differs from the one Tarski provides in yet another respect. Since Bolzano does not require that all non-logical ideas must be substituted under variation, but defines deducibility as a three-place relation holding between a collection of premises, a collection of conclusions and an explicitly given collection of variable ideas, his concept is broader than the concept of logical consequence. According to Bolzano's definition, the proposition [Caius has an immortal soul] is deducible from the proposition [Caius is a man] with respect to the idea [Caius]. If, on the other hand, the proposition [All men have immortal souls] is added as a further premise, deducibility does not only hold with respect to the idea [Caius], but with respect to all non-logical ideas occurring in one of the propositions involved, viz. with respect to the collection of ideas [Caius], [man] and [immortal soul]. In this case logical deducibility obtains (WL, §225 [II. 392]). ${ }^{16}$ The concept of deducibility will become important when comparing Bolzano's grounding trees to current notions of normal proofs. In that context we will consider grounding trees with simultaneous deducibility.

\section{Bolzano's concept of grounding}

\subsection{The general idea}

In my opinion, the most important of all relations that can hold between truths obtains when some of them form a ground and others their consequence. $^{17}$ (WL, $§ 198[$ [I.339])

In order to communicate the general idea underlying the grounding relation, Bolzano discusses some examples, on the basis of which he delimits grounding from other relations with which it might be confused, the most prominent candidate being his relation of deducibility. As already mentioned at the outset, grounding is an objective ground-consequence relation among true propositions that is explanatory

\footnotetext{
${ }^{16}$ This example is also discussed in Shapiro (2005), 655-658. Note that what counts as a logical idea in the Bolzanian sense differs from what we nowadays call a logical constant. Logical ideas in the Bolzanian sense include, for example, [has] and [truth].

${ }^{17}$ Das merkwürdigste aller Verhältnisse, die zwischen Wahrheiten Statt finden, ist meiner Meinung nach jenes der Abfolge, vermöge dessen einige der Grund von gewissen anderen und diese dagegen die Folge jener sind.
} 
in nature. Deducibility is an objective relation in the very same sense. Both relations hold among propositions in themselves and thus obtain independently of our judgments and our knowledge (cf. WL, §198). What distinguishes grounding from deducibility is primarily the explanatory force which the grounding relation has, but the deducibility relation lacks. In order to illustrate the difference between deducibility and grounding, Bolzano gives the following examples.

In WL he explains that the truth [The thermometer stands higher in summer than in winter] is grounded in the truth [It is warmer in summer than in winter], and not vice versa (WL, §162 [II.192]). Those propositions are, however, mutually deducible from each other with respect to the ideas [summer] and [winter], and, usually, we are led from knowledge of the former to knowledge of the latter.

In his work Von der Mathematischen Lehrart ${ }^{18}$ Bolzano provides a further example for grounding taken from geometry. He considers the truths [For every two points $a$ and $b$, there is a third point $c$ such that $c a=c b=a b$ ] and [Every pair of circles, one described around the center $a$, the other around $b$, both with a radius $a b$ and lying in one and the same plain containing these points intersects] (cf. Bolzano (1981), §13). Bolzano asserts that the second truth is grounded in the first one and not the other way around, although we can of course infer the truth of the first proposition from the truth of the second one, just as Euclid did. Deducibility holds reciprocally with respect to $[a],[b]$ and $[c]$.

The examples show that Bolzano's concept of grounding is compatible with his notion of deducibility, i.e., there are instances of grounding such that the consequence is simultaneously deducible from its ground with respect to some collection of variable ideas. At the same time, the examples also make clear that deducibility is not sufficient for grounding. While in the examples above deducibility holds mutually, grounding holds in one direction only. The question whether deducibility is a necessary condition for grounding is highly contentious, and I will not go into this debate here. ${ }^{19}$

\subsection{Grounds and consequences}

Bolzano has to acknowledge that he is not able to provide an explicit definition of his notion of grounding, but that best he can do is indicate some of its specific properties (WL, §203 [II.352 f.]). He first discusses several properties of the grounding relation that primarily concern the order-relatedness of the propositions standing in that relation and then presents several 'criteria' that take into account the internal buildup of the propositions as well. Several of those 'criteria' appear to hold in the realm of conceptual truths only. A conceptual truth (Begriffswahrheit) is a truth which is built up from conceptual ideas only and does not contain any occurrence of an intuition (Anschauung), i.e. a simple idea which represents exactly one object, such as, for example, the idea expressed by the demonstrative pronoun 'this' in its ostensive use

\footnotetext{
${ }^{18}$ Bolzano, B. (1981). Von der Mathematischen Lehrart. J. Berg (ed.). Stuttgart: Friedrich Frommann-Holzboog. English translation: On the Mathematical Method. In: Rusnock, P. and R. George (eds.). (2004). On the Mathematical Method and Correspondence with Exner. Amsterdam/New York: Rodopi.

${ }^{19} \mathrm{On}$ the one hand, Bolzano claims that it seems 'quite probable' to him that deducibility is a necessary condition for grounding; on the other hand, he provides a counterexample to that claim (cf. WL, §200). For a thorough discussion of the counterexample and its impact on the relation between deducibility and grounding, see Betti (2010), ch.5; Tatzel (2003), 249-253.
} 
(cf. WL, $\S \S 72,73,133$ ). Prime examples of conceptual truths include, according to Bolzano, truths of mathematics, metaphysics and theology (cf. WL, §133).$^{20}$ Since it is only with respect to conceptual truths that Bolzano is able to specify some more specific 'criteria' for grounding, I will mainly focus on those throughout the paper.

In the following I will provide a thorough discussion and reconstruction of the properties that characterize Bolzano's grounding relation. What complicates matters is the fact that there is, strictly speaking, not one grounding relation, but there are different relations falling under the concept of grounding: immediate and mediate, complete and partial ones.

Bolzano's guiding idea underlying his concept of grounding seems to be this: for every true proposition which can be grounded at all, there is a collection of true propositions making up its complete immediate ground. Since Bolzano takes it that this collection always has further consequences next to the given one, he initially introduces grounding as a relation between two collections of true propositions: a complete ground (vollständiger Grund) and its direct complete consequence (vollständige Folge). The individual truths making up those collections are called partial grounds (Theilgründe) or partial consequences (Theilfolgen), respectively (WL, §198 [II.341]).

One aspect that all those different notions of grounds and consequences have in common is that they can comprise true propositions only. Unlike deducibility, which can hold among false propositions as well, the grounding relation can only obtain among true ones. Bolzano claims:

I claim that the terms of ground and consequence in their proper senses can only be applied to truths, whether individual truths or entire collections of them. Thus a ground as well as a consequence in the strict sense must be either an individual truth or a collection of several. ${ }^{21}$ (WL, §203 [II.253])

Bolzano explains that a complete ground can consist of a single or several truths, whereas its complete immediate consequence always comprises at least two true propositions (WL, §205). Among the partial immediate consequences of any collection of true propositions there is, according to Bolzano, a truth which states that each of the propositions figuring as part of the collection is true. ${ }^{22}$ Thus, every single truth and every collection of truths has an immediate consequence (cf. WL, §§206 [II.259 f.], 214 [II.374]). It is, however, not the case that every single truth and every collection of truths has a complete immediate ground as well. First, there are truths which lack any ground at all. Bolzano calls those truths which cannot be further grounded fundamental truths (Grundwahrheiten) (WL, §214 [II.375]). Second, there are collections

\footnotetext{
${ }^{20}$ For Bolzano's distinction between conceptual and empirical propositions in the context of grounding, see Tatzel (2001), ch.2.1.

${ }^{21}$ Ich behaupte nämlich, daß es ausschließlich nur Wahrheiten, einzelne oder ganze Inbegriffe derselben sind, denen die Benennungen des Grundes und der Folge, wenn sie in ihrer eigentlichen Bedeutung genommen werden, beigelegt werden dürfen. Was ein Grund, und ebenso auch, was eine Folge heißen soll im strengen Sinne, muß eine Wahrheit, irgend eine einzelne oder ein ganzer Inbegriff mehrer Wahrheiten seyn.

${ }^{22}$ This claim appears to play an important role when it comes to determining the relational properties of the grounding relation. Tatzel (2001), who provides an axiomatic reconstruction of Bolzano's theory of grounding, therefore adopts it as one of his three axioms (cf. Tatzel (2001), ch.1.3; Tatzel (2002), ch.6).
} 
of true propositions for which there is just no single collection in which all the propositions are jointly grounded. Rather, every proposition occurring in the collection has its own complete ground (cf. WL, $\S 213$ [II.372 f.]). Those different complete grounds cannot be taken as jointly grounding the collection in question. Bolzano holds that the relation between a complete ground and its complete immediate consequence is 'more intimate' than that it would allow for such combinations (WL, $\$ 210$ [II.368]). Since each non-fundamental truth contained within the complete ground of a given proposition is again grounded in some collection or other, and so forth, the concept of grounding gives rise to the notion of grounding trees. Each truth occurring in such a tree is linked to the tree's conclusion via a chain of immediate grounding steps.

Bolzano establishes most of the properties of grounding on the basis of the immediate relation between a complete ground and its complete consequence, although it is surely the relation between a complete ground and one of its partial consequences Bolzano is mostly interested in. This is the relation that comes about when asking for the ground of a given truth, and that, when iterated, gives rise to the notion of grounding trees. In addition, Bolzano considers the immediate relation between partial grounds and partial consequences. The examples we considered above (section 3.1) are instances of that relation. In the following section I will discuss the relational properties of the different immediate grounding relations (WL, §§204-215). In section 3.4 I will deal with the basic properties of the mediate grounding relation and the concept of grounding trees (WL, §216-220). In section 3.5 I will discuss the more specific 'criteria' for grounding which concern the internal buildup of the propositions figuring as grounds and consequences (WL, §221).

\subsection{Immediate grounding}

In this section I will discuss the general relational properties of the different variants of immediate grounding, which Bolzano puts forth in WL $\S \S 204-215$, following Bolzano's order in WL as closely as possible. In order to be able to distinguish the different variants of the immediate grounding relation, I introduce some notation. In the following, let $\Gamma, \Gamma^{\prime}, \Delta, \Delta^{\prime}$ and $\Theta$ be variables ranging over non-empty collections of true propositions, and let $\phi, \phi^{\prime} \psi, \psi^{\prime}$ and $\xi$ range over individuals truths. I will use ' $\Vdash$ ' to denote the immediate relation between a complete ground and either one of its partial or its complete consequence (complete immediate grounding). ${ }^{23}$ The relation between a partial ground and one of its partial immediate consequences will be denoted by ' $\triangleright$ ' (partial immediate grounding).

(G1) $\Gamma \Vdash \phi$ iff $\Gamma$ is the complete immediate ground of $\phi$

(G2) $\Gamma \Vdash \Delta$ iff $\Delta=\{\phi: \Gamma \Vdash \phi\}$

(G3) $\psi \triangleright \phi$ iff there is some collection $\Gamma$ such that $\psi \in \Gamma$ and $\Gamma \Vdash \phi$

\footnotetext{
${ }^{23}$ There is no risk in conflating the relation between a complete ground and one of its partial immediate consequences with the relation between a complete ground and its complete immediate consequence, although the same sign is used in both cases, since complete grounds are always collections, never individual truths. Each complete consequence comprises at least two true propositions (cf. WL, §205).
} 


\subsubsection{Irreflexivity}

In $\S 204$ Bolzano starts out by postulating the irreflexivity of the complete immediate grounding relation. He writes:

[W] can claim neither of an individual truth $A$, nor of a collection of truths $A, B, C, D, \ldots$ that they stand to themselves in the relation of ground to consequence, i.e., that they are their own ground, their own consequence. This already lies within the concepts I connect with the words ground and consequence. If I think of something as a ground, I think of something else of which it is the ground. If I think of something as a consequence, then I also think of something else of which it is the consequence. ${ }^{24}$ (WL, $\S 204$ [II.356])

Bolzano takes it to be a basic property of the grounding relation that a complete ground and its complete immediate consequence can never be identical.

Irreflexivity $_{\Vdash}(\mathrm{WL}, \S 204): \Gamma \Vdash \Gamma$

Yet, Bolzano does not only hold that a complete ground must not entirely coincide with its complete immediate consequence, but he assumes furthermore that a complete ground and its complete immediate consequence cannot even have a single proposition in common, i.e., if $\Gamma \Vdash \Delta$, then $\Gamma \cap \Delta=\emptyset$. In $\S 210$, he explains that 'no one will admit' that a truth can be part of both the complete ground and its complete immediate consequence (WL, §210 [II.368], cf. also WL, §218). From the fact that a complete ground and its complete immediate consequence cannot overlap, it follows that no truth can be part of its complete immediate ground, i.e., if $\Gamma \Vdash \phi$, then $\phi \notin \Gamma$. The immediate relation between partial grounds and partial consequences is hence irreflexive, just as the complete relation. Partial grounds and their immediate partial consequences can never be identical.

Irreflexivity $(\mathrm{WL}, \S 210): \phi \not \phi$

\subsubsection{Uniqueness}

In $\S 206$ Bolzano states that there is a one-to-one correspondence between complete grounds and complete consequences. As he takes the complete consequence of a given collection to comprise all and only those truths which are immediately grounded in that collection, one and the same complete ground surely cannot have different complete consequences (WL, §206 [II.359]). For every complete ground, the collection of truths figuring as its complete immediate consequence is thus uniquely determined, i.e., if $\Gamma \Vdash \Delta$ and $\Gamma \Vdash \Delta^{\prime}$, then $\Delta=\Delta^{\prime}$.

Bolzano also establishes that one and the same complete consequence can never be grounded in two different collections of true propositions. Since among the partial

\footnotetext{
${ }^{24}[\mathrm{~W}]$ ir können weder von einer einzelnen Wahrheit $A$, noch von einem Inbegriffe mehrer Wahrheiten $A, B, C, D, \ldots$ behaupten, sie ständen zu sich selbst in dem Verhältnisse einer Abfolge, d.h. sie wären der Grund und die Folge von sich selbst. So nämlich liegt es schon in den Begriffen, die ich mit den Worten Grund und Folge verbinde. Stelle ich mir vor, daß etwas Grund sey, so stelle ich mir dabei noch etwas anderes vor, von dem es Grund sey; denke ich mir, daß etwas Folge sey, so denke ich mir noch etwas anderes daneben, von dem es eine Folge seyn soll.
} 
immediate consequences of any collection of true propositions there is always the truth which asserts that each of the propositions figuring as part of the collection is true, the complete immediate consequences of two different complete grounds cannot be entirely identical (WL, §206 [II.359 f.]). To every complete consequence, there corresponds a unique complete immediate ground, i.e., if $\Gamma \Vdash \Delta$ and $\Gamma^{\prime} \Vdash \Delta$, then $\Gamma=\Gamma^{\prime}$.

However, Bolzano does not merely require that every complete consequence has a unique complete immediate ground, but even demands that this complete ground is uniquely determined already if only a partial consequence is given. He actually holds that for every single non-fundamental truth there is a unique collection of true propositions making up its complete immediate ground..$^{25}$

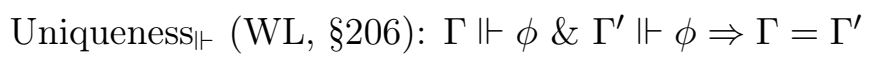

$\S 206$ contains a puzzling passage though. When arguing for the claim that every complete consequence is uniquely grounded, Bolzano explains that there are cases where it seems that different complete grounds have entirely the same complete immediate consequence, but that in fact they only have some of their partial consequences in common (cf. WL, §206 [II.359]). If one and the same proposition could, however, be grounded in different collections, its complete immediate ground would surely not be unique. In order for there to be a unique complete immediate ground for every non-fundamental truth, the complete immediate consequences of any two different complete grounds must have an empty intersection, i.e., if $\Gamma \Vdash \Delta, \Gamma^{\prime} \Vdash \Delta^{\prime}$ and $\Gamma \neq \Gamma^{\prime}$, it must not only hold that $\Delta \neq \Delta^{\prime}$, but also that $\Delta \cap \Delta^{\prime}=\emptyset .{ }^{26}$ Throughout WL it becomes clear that Bolzano considers the uniqueness of the complete immediate ground of a given truth to be a fundamental property of the grounding relation, and we will see the importance of that claim in the course of this paper. In a later passage Bolzano explicitly states that 'there is only one objective ground of any individual truth (as seems to be the case according to $\S 206$ )' (WL, $\S 312$ [III.230]). It is striking that Bolzano here even refers back to $\S 206$. He seems to have overlooked the complications arising from the point he is making in that paragraph.

In $\S 207$ Bolzano moreover immediately makes use of his apparent uniqueness claim in $\S 206$ in order to establish the non-monotonicity of the complete immediate grounding relation. He argues as follows:

[W]e shall not say that a consequence of several truths $A, B, C, \ldots$ is also a consequence of the entire collection of truths $A, B, C, D, E, F, \ldots$ This is clear from what has already been said; for if we were to consider the same truth $M$ or collection of truths $M, N, O, \ldots$ as a consequence of both $A, B, C, \ldots$ and $A, B, C, D, E, F, \ldots$, it would be false to say that the same consequence always has the same grounds. ${ }^{27}$ (WL, $\S 207$ [II.360])

\footnotetext{
${ }^{25}$ Cf. WL, §207 [II.360], §312 [II.230], §528 [IV.266].

${ }^{26}$ Note that from the fact that the complete immediate ground of a given truth is always uniquely determined, it follows that the relation of 'having the same complete immediate ground as' defines an equivalence relation on the collection of all non-fundamental truths and thus yields a partition of that collection.

${ }^{27}$ [E]ine Folge, die sich schon aus den etlichen Wahrheiten $A, B, C, D, \ldots$ ergibt, werden wir nicht als eine Folge des ganzen Inbegriffs der Wahrheiten $A, B, C, D, E, F, \ldots$ ansehen dürfen. Dieses erhellet schon aus dem Vorigen; denn wenn wir einerlei Wahrheit $M$, oder auch einerlei Inbegriff mehrer Wahrheiten $M, N, O, \ldots$ als Folge von $A, B, C, D, E, \ldots$ betrachten dürften: so wäre es ja falsch, daß einerlei Folge auch nur aus einerlei Grunde hervorgehet.
} 
Here Bolzano takes the uniqueness of the complete immediate ground of a given non-fundamental truth for granted. Under the assumption that for both complete and partial consequences the corresponding complete immediate ground is uniquely determined, it follows that neither the relation between a complete ground and its complete immediate consequence, nor the relation between a complete ground and one of its partial immediate consequences can be monotone. The complete immediate grounding relation does not allow for weakening, i.e., if $\Gamma \Vdash \phi$ and $\Gamma \subset \Theta$, then $\Theta \Vdash \phi$.

\subsubsection{Asymmetry}

In $\S 209$ Bolzano stipulates the asymmetry of both the relation of partial and complete immediate grounding. He writes:

The question [...] arises whether the relation of ground and consequence can $[\ldots]$ be mutual, i.e., whether there is a pair of truths or of collections of truths which are so constituted that each may rightly be considered the ground as well as the consequence of the other. I incline towards a negative answer to this question, for complete grounds and consequences as well as for partial ones. ${ }^{28}$ (WL, $§ 209$ [II.362])

Unlike deducibility, the grounding relation is an asymmetric relation: it is a oneway relation. No collection of truths can be grounded in its corresponding complete immediate consequence.

$$
\text { Asymmetry }_{\Vdash}(\mathrm{WL}, \S 209): \Gamma \Vdash \Delta \Rightarrow \Delta \Vdash \Gamma
$$

Bolzano derives the asymmetry of the complete immediate grounding relation from the fact that among the partial consequences of any collection of true propositions there is always the truth which asserts that each proposition figuring as part of the collection is true. He claims that it would be 'absurd' to consider that proposition a partial immediate ground of the collection in question (WL, §209 [II.362]).

Bolzano does not only deny that the relation between a complete ground and its complete immediate consequence can be a mutual one, but assumes that the immediate relation between partial grounds and partial consequences is asymmetric as well. A partial consequence of a proposition cannot at the same time be a partial ground of that proposition.

$$
\text { Asymmetry }_{\triangleright}(\mathrm{WL}, \S 209): \psi \triangleright \phi \Rightarrow \phi \not \psi
$$

The asymmetry of the partial immediate grounding relation does not follow from the properties of grounding Bolzano introduced so far. Bolzano seems to assume that asymmetry is a basic property of grounding. In both the examples we considered above (section 3.1) we have a case of two propositions which are mutually deducible

\footnotetext{
${ }^{28}$ Es entstehet somit die Frage, ob das Verhältniß der Abfolge ebenso wechselseitig, wie das der Ableitbarkeit, Statt finden könne, d.h. ob es nicht Paare von Wahrheiten oder von ganzen Inbegriffen mehrer Wahrheiten gebe, die so beschaffen sind, daß man jeden der beiden verglichenen Theile mit gleichem Rechte als Grund sowohl als auch als Folge von dem andern ansehen könne? - Ich neige mich zu der verneinenden Beantwortung dieser Frage; und dieß zwar sowohl, wenn unter Grund und Folge die vollständigen, als auch wenn bloße Theilgründe und Theilfolgen verstanden werden sollen.
} 
from each other, while grounding holds in one direction only. As a ground-consequence relation which is explanatory in nature, grounding is directed. Explanations must not be circular.

Note that although for neither an individual truth nor for a collection of truths there can be some truth or a collection of several with respect to which the truths in question are both ground and consequence, they can of course at the same time be grounds with respect to some truths and consequences with respect to others (cf. WL, §208).

\subsubsection{Antitransitivity}

From the uniqueness of complete immediate grounding it follows that the complete immediate grounding relation is antitransitive. The complete immediate ground of a collection of true propositions cannot at the same time be considered the complete immediate ground of that collection's complete consequence, which would otherwise be grounded in two different collections, i.e., if $\Gamma \Vdash \Theta$ and $\Theta \Vdash \Delta$, then $\Gamma \Vdash \Delta$ (WL, $\S 213$ [II.371 f.]).

Much more interesting, however, is the case 'where there is no such ground of the ground, because the ground actually consists of several consequences, which therefore have diverse grounds' (WL, $\S 213$ [II.373]). As we have seen earlier (section 3.2), there are collections of true propositions for which there is no single complete immediate ground, but which are such that each of the propositions figuring as part of the collection is separately grounded. Assume that we are given a collection of truths $\psi_{1}, \ldots, \psi_{n}$ which is such that $\psi_{1}$ is grounded in a collection $\Psi_{1}, \psi_{2}$ in a collection $\Psi_{2}$, and so forth. Now let $\phi$ be a partial consequence of the collection $\psi_{1}, \ldots, \psi_{n}$. Bolzano argues that it is not permissible to consider the collection of all partial grounds contained in one of the collections $\Psi_{i}(1 \leq i \leq n)$ the complete ground of $\phi$ (cf. WL, $\S 213$ [II.372 f.]).

Antitransitivity $_{\Vdash}(\mathrm{WL}, \S 213): \Psi_{1} \Vdash \psi_{1} \& \ldots \& \Psi_{n} \Vdash \psi_{n} \& \psi_{1}, \ldots, \psi_{n} \Vdash \phi \Rightarrow$

$$
\Psi_{1} \cup \cdots \cup \Psi_{n} \not \forall \phi
$$

The complete immediate grounds of the truths figuring as part of the complete immediate ground of a given true proposition cannot be considered as jointly grounding that proposition, since the immediate grounding relation is unique (cf. WL, §206) and does not allow for such combinations (cf. WL, §210).

It is important to note that partial immediate grounding cannot be claimed to be antitransitive as well, since it is not excluded that the truths figuring as part of a given complete immediate ground partially ground one another. According to Bolzano, 'there are [...] truths which stand to each other as ground to consequence (at least as partial ground to a partial consequence), and which can be combined as parts to bring about a new consequence' (WL, $§ 212$ [II.370]). Hence, if $\xi$ is a partial immediate consequence of some truth $\psi$, it is possible that both $\xi$ and $\psi$ figure in the complete immediate ground of some other truth $\phi$. In this case we have that $\psi \triangleright \xi$, $\xi \triangleright \phi$ and $\psi \triangleright \phi$.

Since the complete immediate grounding relation is antitransitive, we are not allowed to consider the grounds of some collection as jointly grounding that collection's consequence. With the concept of mediate grounding Bolzano nevertheless provides a notion that enables us to relate a given truth to its remote grounds. 


\subsection{Mediate grounding}

Given the relation between a non-fundamental truth and its complete immediate ground, it is of course possible to go on and ask for the grounds of those truths again, and so forth, until one finally reaches fundamental truths which cannot be further grounded. ${ }^{29}$

When someone, beginning with a truth $M$, asks for its ground, and finds it either in the individual truth $L$ or the several truths $I, K, L, \ldots$, proceeds to ask for the grounds of the latter truths, and so on, continuing as long as grounds may still be indicated, I speak of an ascension from consequences to their grounds [Geschäft des Aufsteigens von der Folge zu ihrem Grunde]. ${ }^{30}$ (WL, §216 [II.376])

We have seen (section 3.2) that it is not the case that the complete immediate ground of a given truth is always grounded in a single collection. Rather, every truth figuring as part of the complete ground might have its own complete ground. The procedure of 'ascension from consequences to their grounds' therefore gives rise to the notion of grounding trees. It implies whole grounding systems which can be pictured as tree structures. Bolzano provides the following 'graphic representation' as an example of a grounding tree (WL, $\S 220$ [II.382]): ${ }^{31}$

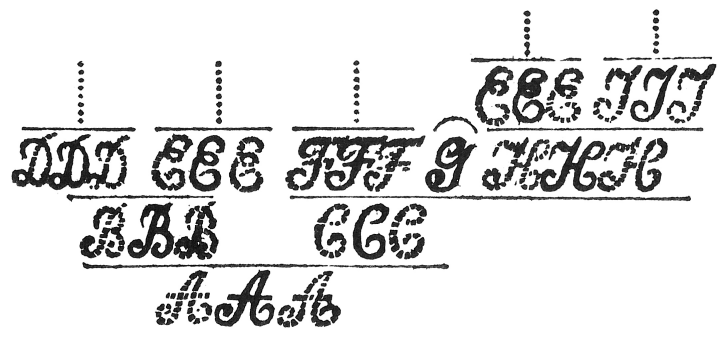

Figure 1: A grounding tree

Here the procedure of 'ascension from consequences to their grounds' starts with the truth $A$. The collection of $B$ and $C$ makes up its complete immediate ground. The complete immediate ground of $B$ is given by the collection of $D$ and $E, C$ is completely grounded in $F, G$ and $H$, and so on. $G$ is a fundamental truth. The vertical dots over the letters $D, E, F, J, \ldots$ indicate that one can proceed ascending to grounds there. According to Bolzano, if one starts out with a conceptual truth, the procedure of 'ascension from consequences to their grounds' always terminates after finitely many steps, when one finally reaches fundamental truths (cf. WL, §221.3

\footnotetext{
${ }^{29}$ In the realm of conceptual truths, the grounding relation is well-founded (cf. WL, §221.3).

${ }^{30}$ Wenn Jemand anfangend bei einer gegebenen Wahrheit $M$ nach ihrem Grunde fragt, und falls er diesen in der einzelnen Wahrheit $L$, oder in den mehren Wahrheiten $I, K, L, \ldots$ gefunden, nun wieder fragt nach dem Einen oder den mehren Gründen, die diese Eine oder mehre Wahrheiten haben, und dieses so lange, als sich nur Gründe angeben lassen, fortsetzt: so nenne ich dieses Geschäft das Geschäft des Aufsteigens von der Folge zu ihrem Grunde.

${ }^{31}$ Sebestik remarks: 'In the [WL] we also witness the appearance, for the first time in the history of logic, of proof trees, i.e. diagrams showing the dependence of theorems on their grounds, axioms and auxiliary truths' (Sebestik (2012), ch.7).
} 
[II.385 f.]). By the multiple occurrences of each of the letters, besides $G$, Bolzano indicates that the corresponding complete immediate consequences might comprise further truths. Those further truths, which are represented by fainter letters, are neither immediate nor mediate grounds of $A$, and might therefore be neglected if one is just interested in the truths grounding $A$ (cf. WL, $\S 220$ [II.382 f.]). They are simply truths having the same complete immediate grounds as the respective boldface truths which ones comes across when ascending from $A$ to its grounds. ${ }^{32}$

In line with the procedure of 'ascension from consequences to their grounds' we can provide the following inductive definition of a grounding tree:

(G4) (i) If $\psi_{1}, \ldots, \psi_{n} \Vdash \phi$, then $\frac{\psi_{1} \ldots \psi_{n}}{\phi}$ is a grounding tree for $\phi$ with leaves $\left\{\psi_{1}, \ldots, \psi_{n}\right\}$.

(ii) If $\begin{gathered}\theta_{1} \ldots \theta_{m} \\ \Pi\end{gathered}$ is a grounding tree for $\phi$ with leaves $\left\{\theta_{1}, \ldots, \theta_{m}\right\}$ and $\phi$

$$
\begin{aligned}
& \xi_{1}, \ldots, \xi_{k} \Vdash \theta_{i}(1 \leq i \leq m) \text {, then } \theta_{1} \ldots \theta_{i-1} \frac{\xi_{1} \ldots \xi_{k}}{\theta_{i}} \theta_{i+1} \ldots \theta_{m} \text { is }
\end{aligned}
$$

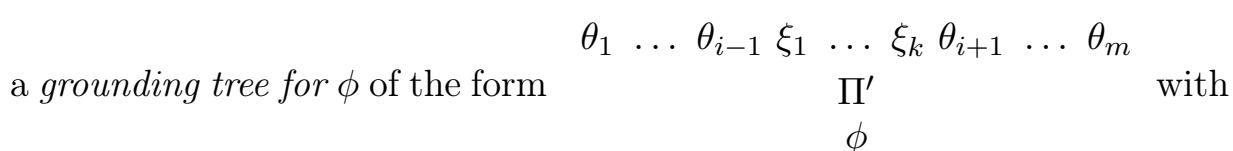

$$
\begin{aligned}
& \text { leaves }\left\{\theta_{1}, \ldots, \theta_{i-1}, \xi_{1}, \ldots, \xi_{k}, \theta_{i+1}, \ldots, \theta_{m}\right\} \text {. }
\end{aligned}
$$

We say that a grounding tree is a complete grounding tree for $\phi$ if its leaves comprise fundamental truths only.

A complete grounding tree contains for every truth occurring in it (apart from the fundamental truths on top, which cannot be further grounded) its complete immediate ground as well. And every truth contained within a grounding tree (besides the root) forms a partial immediate ground of another truth in the tree. Each step in a grounding tree consists in the relation between a single true proposition and its complete immediate ground. Those are the steps we make when ascending from consequences to their grounds. Since Bolzano takes the complete immediate ground of a given true proposition to be uniquely determined, there is one and only one grounding tree for every non-fundamental truth (cf. WL, §312 [III.230], §528 [IV.266]). Here is becomes clear that the uniqueness requirement plays a central role in Bolzano's theory of grounding (cf. section 3.3.2).

Bolzano calls the truths 'which we discover when we ascend from a given truth [...] as consequence to its ground' and which are thus part of the grounding tree of that truth, its supporting truths (Hülfswahrheiten) (WL, §217 [II.377 f.]). We can capture the notion of a supporting truth of a proposition $\phi$ by taking recourse to the chains in the grounding tree of $\phi$. All the boldface letters in the example of a grounding tree in Fig. 1 above (besides $A$ itself) are supporting truths of $A$, and each

\footnotetext{
${ }^{32}$ If we consider the relation of 'having the same complete immediate ground as' as defining an equivalence relation on the set of all non-fundamental truths, the truths grouped together here correspond precisely to the equivalence classes modulo that relation. Cf. footnote 26.
} 
of them is linked to $A$ via chain of partial immediate grounding steps. We can thus define the concept of a supporting truth in terms of the relation of partial immediate grounding. Roughly speaking, a truth $\psi$ is a mediate ground of a truth $\phi$ just in case in the grounding tree of $\phi$ there is a path of partial immediate grounding steps running from $\psi$ to $\phi .^{33}$

(G5) $\psi$ is a supporting truth of $\phi(\psi \triangleright \triangleright \phi)$ iff there is a chain $\left\langle\xi_{1}, \ldots, \xi_{n}\right\rangle$ such that

(i) $\xi_{1}=\psi$

(ii) $\xi_{n}=\phi$

(iii) $\forall i(1 \leq i<n): \xi_{i} \triangleright \xi_{i+1}$.

Every truth occurring in such a grounding chain (besides the last one) constitutes a partial immediate ground of its successor. In complete grounding trees, there are maximal grounding chains running from a fundamental truth on top to the tree's conclusion. In the grounding tree for $A$ in Fig. 1 above, for example, the sequence of truths $\langle G, C, A\rangle$ constitutes a maximal chain. Since Bolzano assumes that the procedure of 'ascension from consequences to their grounds' terminates after finitely many steps if one starts out with a conceptual truth, every maximal chain in a complete grounding tree of a conceptual truth is of finite length. According to Bolzano, grounding trees of conceptual truths are, however, not only vertically finite in that there are no infinite maximal chains, but he demands furthermore that the number of supporting truths of a given conceptual proposition is finite in general (cf. WL, §221.3). Consequently, grounding trees of conceptual truths must be horizontally finite as well, i.e., the complete immediate ground of a given conceptual truth must never comprise infinitely many propositions. ${ }^{34}$

The relation of 'being a supporting truth of' allows one to relate a given truth to one of its remote grounds. It is the transitive closure of the partial immediate grounding relation.

\footnotetext{
${ }^{33}$ Tatzel also provides a definition of mediate grounding that is spelled out in terms of grounding chains (cf. Tatzel (2001), ch.1.4; Tatzel (2002), ch.7). However, he takes the steps that link the elements of a chain to consist in instances of the relation between a partial or complete ground and the corresponding complete immediate consequence, whereas Bolzano explicitly denies that all truths that are part of the complete immediate consequence of some supporting truth of a given proposition are supporting truths of that proposition as well (cf. WL, §220 [II.382 f.]). Remember that the grounding relation does not allow for weakening (cf. section 3.3.2).

${ }^{34}$ The fact that the number of supporting truths of a conceptual truth is finite and hence that grounding trees of conceptual truths are both vertically and horizontally finite follows from Bolzano's proof of the existence of fundamental truths in the realm of conceptual propositions (cf. WL, §221.3 [II.385 f.]). Bolzano supposes that there are only finitely many simple conceptual ideas and concludes that the collection of conceptual truths which contain at most as many occurrences of simple conceptual ideas as a given truth $\phi$ must therefore be finite as well. Since the supporting truths of $\phi$ must be part of that collection, as will become clear later (cf. section 3.5), their number cannot be infinite. From this it follows immediately that grounding trees cannot be horizontally infinite. Since in each chain of a grounding tree each truth can occur only once, due to the irreflexivity of the relation of 'being a supporting truth of', grounding trees of conceptual truths must moreover be vertically finite. Note that Bolzano seems to presuppose here that every conceptual proposition contains at most finitely many occurrences of simple ideas and that there are only finitely many modes of combination. For a discussion of the claim that grounding trees must be both vertically and horizontally finite, see also Tatzel (2001), ch.2.5.
} 
Transitivity $_{\triangleright \triangleright:}: \downarrow \triangleright \xi \& \xi \triangleright \triangleright \phi \Rightarrow \psi \triangleright \triangleright \phi$

The relation of 'being a supporting truth of' is moreover irreflexive. In $\S 218$ Bolzano claims that no truth can be a supporting truth of itself (WL II, §218 [II.378]). He again takes this to be a basic property of grounding.

Irreflexivity ${ }_{\triangleright \triangleright}(\mathrm{WL}, \S 218): \phi \triangleright \triangleright \phi$

Although no truth can be a supporting truth of itself, it is not excluded that one and the same truth occurs several times among the supporting truths of a given true proposition (WL, §219). According to Bolzano, it is possible that the truths figuring as part of a given complete immediate ground partially ground one another (cf. WL, §212). If, for example, a truth $\xi$ is a partial consequence of a truth $\psi$, and both $\xi$ and $\psi$ are part of the complete immediate ground of some truth $\phi$ (cf. section 3.3.4), then the supporting truths of $\phi$ - and hence the grounding tree of $\phi$ - contain multiple occurrences of $\psi$. Note also that in the example of a grounding tree in Fig. 1 above the truth $E$ is part of both the complete immediate ground of $H$ and the complete immediate ground of $B$. One and the same truth can have multiple occurrences within the same grounding tree. Due to the irreflexivity of the relation of 'being a supporting truth of', a truth cannot, however, occur several times within the same grounding chain of a tree.

From the transitivity and irreflexivity it follows that the relation of 'being a supporting truth of' is asymmetric as well.

Asymmetry $_{\triangleright \triangleright:} \psi \phi \triangleright \phi \Rightarrow \phi \triangleright \triangleright \psi$

Being irreflexive, asymmetric and transitive, the relation of 'being a supporting truth of' defines a strict partial order on the collection of truths occurring in a grounding tree.

A grounding tree for a given true proposition, or more precisely, its written representation, constitutes a proof for that truth. In fact, Bolzano calls 'anything that we think someone may, by directing his attention to it, use in order either to form a judgment [...] that he had not previously formed, or else to form it with a higher degree of confidence' a proof (WL, $\S 370$ [III.457]), and he holds that by considering the grounds of a given proposition one 'quite naturally' comes to recognize its truth (WL, §312 [III.228]). In contradistinction to other proofs (such as proofs based on the deducibility relation, for example) a grounding tree does not only demonstrate the truth of its respective conclusion, but also reveals its grounds. A grounding tree for a given truth constitutes a unique explanatory proof or, as Bolzano calls it, a demonstration (Begründung) for that truth, showing why the conclusion is true, whereas all other proofs are considered as mere certifications (Gewißmachungen) (WL, §525 [IV.261]). According to Bolzano, in at least each 'rigorously scientific presentation' of a conceptual science, each non-fundamental truth should be proven by means of an explanatory proof based on the grounding relation (WL, §553 [IV.330], §§401, 525, 602). The grounding relation is thus of crucial importance for the ideal buildup of scientific theories. 


\subsection{Criteria for grounding}

After having introduced the order-theoretic properties of the grounding relation that we have discussed so far, Bolzano sets forth to provide some more specific 'criteria' - or rather, characteristic properties - for the grounding relation which concern the internal buildup of the propositions figuring as grounds and consequences. Several of those 'criteria', however, hold in the realm of conceptual truths only. As mentioned earlier, a conceptual truth, such as, for example, a mathematical truth, is a truth which is built up exclusively from conceptual ideas and does not contain any occurrence of an intuition (Anschauung), i.e. a simple idea which represents exactly one object (cf. WL, $\S \S 72,73,133)$. According to Bolzano, conceptual truths are such that 'if they have any ground at all, it must lie in other conceptual truths' (WL, §221.1 [II.384]). The complete immediate ground of a non-fundamental conceptual truth comprises conceptual truths only. I.e., each partial immediate ground of a conceptual truth is itself a conceptual truth.

Homogeneity $(\mathrm{WL}, \S 221.1): \phi$ is conceptual \& $\psi \triangleright \phi \Rightarrow \psi$ is conceptual

Since each supporting truth of a conceptual truth is linked to that truth via a chain of partial immediate grounding steps, all supporting truths of a conceptual truth must be conceptual propositions. The propositions making up the grounding tree of a conceptual truth are hence all conceptual in nature.

A pivotal feature of grounding in the realm of conceptual truths is that it meets what I will call the Complexity Constraint. ${ }^{35}$ It is essentially this property that gives rise to the similarities Bolzano's concept of grounding bears to current notions of normal proofs. The Complexity Constraint consists in the claim that a partial ground of a conceptual truth 'must never be more complex than the latter, though it does not have to be simpler' (WL, $\S 221.2$ [II.384]). But what does it mean for a proposition to be simpler or more complex than another one? After stating the above requirement, Bolzano continues as follows:

Propositions which form the objective ground of a purely conceptual truth must separately contain no more simple parts than the truths which depends upon them. ${ }^{36}$ (WL, §221.2 [II.384])

Bolzano takes the complexity of a proposition to be determined by the number of simple parts it contains. In the passage under consideration he construes his constraint that partial grounds must not be more complex than the corresponding partial consequence as the requirement that a partial ground must contain at most as many simple parts as the consequence does. A proposition thus seems to be considered simpler than another one if it contains fewer simple parts. We have seen earlier that the ultimate constituents of Bolzano's propositions are simple ideas, which are not further decomposable. One and the same idea can occur more than once in a given proposition, and the simple parts of a proposition that Bolzano refers to in the present

\footnotetext{
${ }^{35}$ The term "Complexity Constraint" is also used in Tatzel (2001), ch.2.2, yet Bolzano's requirement is interpreted differently there (cf. footnote 40).

${ }^{36}$ Die Sätze, aus welchen der objektive Grund einer Wahrheit, die eine reine Begriffswahrheit ist, bestehet, dürfen ein jeder im einzelnen nie mehr einfache Teile, als diese selbst hat, enthalten.
} 
context should accordingly be understood as occurrences of simple ideas. ${ }^{37}$ We have previously defined the collection of all occurrences of simple ideas in which a given proposition $\phi$ can ultimately be decomposed as its simple content, denoted by ' $C_{\phi}$ ' (cf. section 2). The simple content provides a measure for the complexity of a proposition. With this terminology at hand, Bolzano's requirement can be restated as follows: the simple content of each partial ground $\psi$ of a conceptual truth $\phi$ must comprise at most as many occurrences of simple ideas as the simple content of $\phi$, i.e., if $\psi \triangleright \phi$, then $\operatorname{card}\left(C_{\psi}\right) \leq \operatorname{card}\left(C_{\phi}\right)$.

There are, however, several passages in Bolzano's work where he appears to demand more. He seems to require not only that a partial ground must not contain more occurrences of simple ideas than its consequence does, but also that it should ideally not contain any occurrence of a simple idea that is not part of the consequence as well. In other words, at least in the ideal case, the simple content of each partial ground should form a subcollection of the simple content of the corresponding partial consequence. This seems to be what Bolzano has mind when he writes that 'the more complex truth, i.e., the one which not only contains the ideas which are found in the simpler truth but also several others besides, will be grounded in the more simple one (§221)' (WL, $\S 609$ [IV.449]). Bolzano actually uses the expressions 'simpler' and 'more complex' in two different ways. ${ }^{38}$ In the passage just quoted a proposition $\phi$ is considered simpler than a proposition $\psi$ if and only if the simple content of $\phi$ forms a proper subcollection of the simple content of $\psi$. In this case, $\psi$ is more complex than $\phi$.

Further evidence for the fact that Bolzano indeed embraces the stronger requirement is provided by what he writes when he is concerned with the question how we can discover the grounds of a given conceptual truth. In that context he explains:

An analysis of the given proposition $[M]$ that extends to its simple parts [...] must be our first business in this problem. Next, we must construct from the parts we have discovered in the proposition $M$ propositions that are simpler or at least not more complex than $M[\ldots]{ }^{39}$ (WL, $\S 370$ [III.496])

According to Bolzano, the partial grounds of the proposition $M$ will be among those truths that can be constructed from the occurrences of simple ideas in which $M$ can be decomposed. This passage makes clear that Bolzano assumes that in the ideal case the partial grounds of a proposition are constituted of only such occurrences of

\footnotetext{
${ }^{37}$ It is important that we consider the occurrences of simple ideas within a given proposition rather than the simple ideas themselves, since otherwise we cannot account for the fact that, for example, [ $\phi$ has truth] has truth] is more complex than $[\phi$ has truth]. For an argument for the claim that the Complexity Constraint has to be spelled out in terms of occurrences of simple ideas, see Tatzel (2001), ch.2.3.

${ }^{38}$ That a proposition $A$ is simpler than a proposition $B$ can either mean that (i) 'all the parts of $A$ along with certain others occur in $B$ ' or (ii) 'the number of simple parts into which $B$ can be analysed exceeds the number of simple parts of $A^{\prime}$ (WL, $\$ 151$ [II.97]). Note that in his work Von der Mathematischen Lehrart Bolzano uses 'simpler' solely in the meaning specified in (i) (cf. Bolzano (1981), §17).

${ }^{39}$ Eine Zergliederung des gegebenen Satzes $[M]$, die sich, sofern wir es vermögen, bis auf dessen einfache Theile erstrecket, wird also wohl unser erstes Geschäft bei dieser Aufgabe seyn müssen. Das Nächste dürfte dann seyn, aus den gefundenen Theilen der Wahrheit $M$ Sätze zu bilden, die einfacher oder doch nicht zusammengesetzter als $M[\ldots]$ wären [...].
} 
simple ideas that are part of the consequence as well. He adds that if additional ideas might be needed after all, 'we must seek to reduce their number as far as possible' (WL, §370 [III.496]). On the basis of the above considerations, I will adopt the following interpretation of Bolzano's constraint: the truths figuring as part of the complete immediate ground of a given conceptual truth should ideally never contain any occurrence of a simple idea that is not part of their consequence, and none of the partial grounds should contain more occurrences of one and the same simple idea than the consequence does. That is, in the ideal case, the simple content of each partial ground is a subcollection - though not necessarily a strict one - of the simple content of the corresponding partial consequence. I will provide the following formulation of the Complexity Constraint, which is suited to capture Bolzano's ideal: ${ }^{40}$

Complexity $_{\triangleright}(\mathrm{WL}, \S 221.2): \psi \triangleright \phi \Rightarrow C_{\psi} \subseteq C_{\phi}$

The crucial idea underlying the Complexity Constraint seems to be that complex concepts need to be explained in terms of their constituent ideas. In the geometrical example that we considered at the outset (section 3.1), for instance, the concept of a circle occurring in the consequence is more complex than the concept of a point occurring in the ground: Bolzano defines a circle as the collection of all points that are equidistant from a given one.

Since the partial immediate grounds of a given truth must never contain any occurrence of a simple idea that is not part of the consequence, and since each of them can contain at most as many occurrences of one and the same simple idea than the consequence does, in each chain of a grounding tree, the propositions become successively more and more complex (or at least not simpler) when proceeding from grounds to consequences. Hence, every simple idea occurring in one of the propositions of a grounding tree forms a constituent of the conclusion as well. I.e., if $\left\langle\xi_{1}, \ldots, \xi_{n}\right\rangle$ is a maximal chain in the complete grounding tree of a given truth $\phi$, then for all $i$ $(1 \leq i<n): C_{\xi_{i}} \subseteq C_{\xi_{i}+1}$ and thus, in particular, $C_{\xi_{i}} \subseteq C_{\phi}$.

Next to the Complexity Constraint, Bolzano formulates two further necessary conditions for grounding which in a certain sense also concern the 'complexity' of the propositions making up the complete immediate ground of a given truth. Those criteria are not explicitly limited to conceptual truths, but are instead restricted to cases of grounding with simultaneous deducibility. Bolzano seems to assume that if a truth is deducible from its complete immediate ground, the collection of truths figuring as ground is as 'simple' as possible for deducing the conclusion in a buildingup fashion that is in line with the Complexity Constraint. First, he demands that in case of simultaneous deducibility each proposition figuring as part of the complete immediate ground of a given truth 'is always the simplest of the propositions that are individually equivalent to it', i.e. of those which are mutually deducible from it (cf. WL, $\$ 212.4$ [II.386 f.]). If we assume that equivalence holds with respect to the same collection of variable ideas relative to which the consequence is deducible from

\footnotetext{
${ }^{40}$ Although it is frequently pointed out that Bolzano requires that the partial grounds of a conceptual truth must be at most as complex as their corresponding consequence, a precise formulation of that claim is rare. A formal account of Bolzano's Complexity Constraint is given in Berg (1962), 152; Tatzel (2001), ch.2.2; Schnieder (2013), ch.7b, yet their interpretation differs from the one I have provided. In those papers the Complexity Constraint is formulated in its weaker form, as a requirement on the cardinality of the simple content of the partial grounds of a conceptual truth.
} 
its ground, by substituting one of the premises by an equivalent one exactly the same propositions remain deducible. Bolzano's requirement amounts then to the claim that of all those propositions which can in principle do the same job the complete immediate ground contains always the simplest one. Second, Bolzano requires that if a truth is deducible from its complete immediate ground, that ground is 'the simplest collection of truths' from which the consequence is deducible, 'provided that always the same ideas are considered variable, and that none of the premises are individually more complex than the conclusion' (WL, §221.5 [II.387]). The number of truths figuring as part of the complete immediate ground must be minimal in the sense that there is no smaller collection of truths from which the consequence could likewise be deduced with respect to the same collection of variable ideas and proceeding from the simple to the more complex as required by the Complexity Constraint.

By those two constraints Bolzano apparently wants to assure that the complete immediate ground of a given truth does never contain any superfluous proposition or simple idea. None of its constituents should be redundant. They all should be necessary for deducing the consequence in a building-up fashion that is in line with the Complexity Constraint. Bolzano's constraints on the simplicity of the complete immediate ground of course carry over to grounding trees which are such that in each immediate grounding step deducibility holds as well. They are supposed to guarantee that all propositions occurring in such a grounding tree and all their simple parts are relevant for deducing the conclusion step by step in a way that is consistent with the Complexity Constraint. Each immediate step in a grounding tree is uniquely determined, and Bolzano's requirements on the simplicity of the complete immediate ground seem to assure that none of those steps involves any proposition or occurrence of a simple idea that is redundant. A grounding tree should not contain any detour, nor should it contain any proposition or simple idea that is not necessary for deducing the conclusion in a building-up fashion.

Driven by those considerations, Bolzano even contemplates to define grounding as a special kind of deducibility, viz., as a deducibility relation that satisfies both the Complexity Constraint and his requirements on the simplicity of the truths figuring as part of the complete immediate ground (cf. WL, $\S \S 221.3$, note $\S 221$ [II.388]). His idea to define grounding in such a way is related to his assumption that a case of deducibility with respect to an explicitly given collection of variable ideas where (i) the premises are such that "none of them, nor even any of their parts may be omitted' for the conclusion still to be deducible with respect to the given collection of variable ideas ${ }^{41}$, where (ii) the premises are moreover the simplest propositions among equivalent ones, and where (iii) none of the premises is more complex than the conclusion, is sufficient for grounding (WL, $\$ 155.26$ [II.123]). It is disputable, however, whether Bolzano can assure all the properties he ascribes to his grounding relation that way (cf. section 4.2.2). ${ }^{42}$

\footnotetext{
${ }^{41}$ Bolzano calls a case of deducibility which satisfies this condition exact deducibility (genaue Ableitbarkeit) (WL, $\S 155.26 \mathrm{ff}$.).

${ }^{42}$ Bolzano's requirements concerning the simplicity of the complete immediate ground of a conceptual truth are not completely unproblematic. For a thorough discussion of Bolzano's 'criteria' and his tentative definition of grounding, see Roski and Rumberg (2013).
} 


\section{Grounding trees and normal proofs}

Bolzano's ideas on grounding, especially the ideas he develops in the context of conceptual truths, bear some resemblance to current notions of normal proofs. Occasionally, parallels have been pointed out between Bolzanian grounding trees and cut-free proofs in Gentzen's sequent calculus. ${ }^{43}$ The most elaborate discussion of the similarities between the two concepts is provided in Tatzel (2001). My thesis is, however, that Bolzano's grounding trees bear an even stronger resemblance to the normal natural deduction proofs employed in proof-theoretic semantics in the tradition of Dummett and Prawitz and further worked out by Schroeder-Heister and others. In proof-theoretic semantics, natural deduction proofs in which the conclusion is derived from its atomic subformulas (governed by an atomic base) by the mere application of introduction rules are taken to display the meaning of complex sentences in terms of their assertibility conditions.

I will now briefly address the parallels between Bolzano's grounding trees and Gentzen's cut-free proofs in the sequent calculus, and then move on to provide a detailed investigation into how far the normal natural deduction proofs considered by Dummett and Prawitz in the context of proof-theoretic semantics can be said to meet the criteria and properties that Bolzano attributes to grounding trees.

\subsection{Grounding trees and normal proofs in Gentzen's sequent calcu- lus}

The sequent calculus is an axiomatic calculus that was developed by Gerhard Gentzen in 1935. ${ }^{44}$ A sequent is a string consisting of two (possibly empty) lists of formulas, $\Gamma$ and $\Delta$, connected by the sequent sign, $\Gamma \longrightarrow \Delta$. The first list is called the antecedent, and the second the succedent. A sequent $\psi_{1}, \ldots, \psi_{n} \longrightarrow \phi_{1}, \ldots, \phi_{m}$ has the same intuitive meaning as the implication $\psi_{1} \wedge \cdots \wedge \psi_{n} \rightarrow \phi_{1} \vee \cdots \vee \phi_{m} \cdot{ }^{45}$ The axioms of Gentzen's sequent calculus are given by sequents whose antecedent and succedent consist of exactly the same single (atomic) formula, $\psi \rightarrow \psi$. From those axioms, the endsequent of a proof is derived by the application of antecedent and succedent rules for the logical constants, which allow for the introduction of that logical constant in the antecedent or succedent, respectively, and several structural rules. Derivations take the form of a tree. Here, the rules for conjunction are given as an example:

- Antecedent rule(s): $\frac{A, \Gamma \longrightarrow \Delta}{A \wedge B, \Gamma \longrightarrow \Delta}, \frac{B, \Gamma \longrightarrow \Delta}{A \wedge B, \Gamma \longrightarrow \Delta}$

- Succedent rule: $\frac{\Gamma \longrightarrow \Delta, A \quad \Gamma \longrightarrow \Delta, B}{\Gamma \longrightarrow \Delta, A \wedge B}$

\footnotetext{
${ }^{43}$ Cf. Berg (1962), 164; Berg (1988), 22; Buhl (1961), 85 f.; Cellucci (1992), 187; Christian (1974), 62; Centrone (2011), $20 \mathrm{ff}$.

${ }^{44}$ See Gentzen (1935).

${ }^{45}$ Since sequents express a logical dependence relation between the formulas occurring in the antecedent and several succedent formulas, they have frequently been compared to Bolzano's concept of deducibility, which allows for multiple conclusions as well. Note, however, that the succedent formulas of a sequent are combined disjunctively, whereas the multiple conclusions in Bolzano's deducibility relation are combined conjunctively. Gentzen's sequents bear, however, a strong resemblance to Bolzano's concept of conditional complementation (bedingte Ergänzung) (WL, §160 [II.168]). See Berg (1962), 117 f.; Cellucci (1992), 179 f.; Siebel (1996), 150 ff.
} 
Among the structural rules is the so-called cut-rule.

$$
\frac{\Gamma_{1} \longrightarrow \Delta_{1}, A \quad A, \Gamma_{2} \longrightarrow \Delta_{2}}{\Gamma_{1} \cup \Gamma_{2} \longrightarrow \Delta_{1} \cup \Delta_{2}}
$$

All the inference rules of the sequent calculus, besides the cut-rule, are such that every formula occurring in one of the premises of a given instance occurs in the respective conclusion as well, at least as a subformula. That is, the sequents figuring as premises in an instance of an antecedent or succedent rule never contain any formula that is not a subformula of one of the formulas occurring in the sequent following as conclusion. Only the cut-rule allows the elimination of formulas from the derivation.

A proof in the sequent calculus is called normal or cut-free just in case it does not contain any application of the cut-rule. Gentzen's Hauptsatz shows that every proof in the sequent calculus can be transformed into a cut-free one. ${ }^{46}$ In every chain of such a cut-free proof, the formulas of the sequents become more and more complex in the course of the derivation, containing the formulas of the preceding sequents as subformulas. Every formula occurring in one of the sequents of a cut-free proof must be a subformula of one of the formulas of the endsequent of the proof as well. This result is formulated by Gentzen in a corollary to his Hauptsatz as the so called Subformula Property (Teilformeleigenschaft). ${ }^{47}$ Gentzen himself describes the properties of a cut-free proof as follows:

Intuitively speaking, these properties of derivations without cuts may be expressed as follows: The S-formulae [i.e. the formulas occurring in the antecedent or succedent of a sequent, AR] become larger as we descend down in the derivation, never shorter. The final result is, as it were, gradually built up from its constituent elements. The proof represented by the derivation is not roundabout in that it contains only concepts which recur in the final result. (Gentzen (1935), 195 f. [Engl. 298])

These peculiarities of cut-free proofs closely correspond to the properties which Bolzano attributes to grounding trees of conceptual truths. In a cut-free proof of Gentzen's sequent calculus as well as in a Bolzanian grounding tree the conclusion is successively built up from its constituent parts. Both cut-free proofs in the sequent calculus and grounding trees proceed from the simple to the more complex, and neither of them contains any part that is not a constituent of the conclusion. Just as every formula occurring in one of the sequents of a cut-free proof is a subformula of one of the formulas of the endsequent of the proof (Subformula Property), any simple idea occurring in one of the propositions of a grounding tree is part of the conclusion as well (Complexity Constraint). For this reason, Christian considers a cut-free proof in the sequent calculus a 'paradigm of a grounding system'48, and Buhl declares that 'Gentzen's investigations give a precise expression to certain Bolzanian ideas' ${ }^{49}$. A major difference between the two concepts consists though in the fact that a cutfree proof, unlike a grounding tree, is not unique. In the sequent calculus, the same

\footnotetext{
${ }^{46}$ Gentzen (1935), 195 [Engl. 298].

${ }^{47}$ Ibid.

${ }^{48}$ Christian (1974), 62; translated by the author.

${ }^{49}$ Buhl (1961), 85; translated by the author.
} 
endsequent can be derived in various ways, whereas, according to Bolzano, there is one and only one grounding tree for every non-fundamental truth. ${ }^{50}$

As mentioned, the most elaborate discussion of the parallels between Gentzen's cut-free proofs in the sequent calculus and Bolzano's grounding trees of conceptual truths is Tatzel (2001). Noticing that the conclusion of a proof in the sequent calculus consists in a sequent of the form $\psi_{1}, \ldots, \psi_{n} \longrightarrow \phi_{1}, \ldots, \phi_{n}$, which has the same intuitive meaning as the implication $\psi_{1} \wedge \cdots \wedge \psi_{n} \rightarrow \phi_{1} \vee \cdots \vee \phi_{n}$, whereas the conclusion of a Bolzanian grounding tree does not consist in a sequent, which expresses itself a consequence relation, but rather in a single proposition $\phi$ of arbitrary structure, Tatzel restricts his investigations to the case of logical truths, which correspond to sequents with an empty antecedent and a single formula in the succedent. That is, Tatzel compares Bolzano's grounding trees to cut-free derivations of an endsequent of the form $\longrightarrow \phi$ from basic sequents of the form $\psi \longrightarrow \psi \cdot{ }^{51}$ In Bolzano's theory of grounding, however, there exists a complete grounding tree for every arbitrary non-fundamental truth, and the fundamental truths on which the tree is based are individual propositions rather than basic sequents that figure as logical axioms. ${ }^{52,53}$

The need of restricting the investigation to the case of logical truths already makes clear that a cut-free proof in the sequent calculus exhibits a completely different structure than a Bolzanian grounding tree. Gentzen's sequent calculus is often viewed as a meta-calculus of the calculus of natural deduction. The sequents consisting of an antecedent and a succedent express dependence relations between assumptions and conclusions as they obtain in natural deduction proofs, while the sequents themselves do not depend on the basic sequents from which they are derived. The complete grounding tree of a given truth, however, is ultimately based on a collection of fundamental truths, and the tree's conclusion 'can be said to be dependent' upon those truths (WL, §217 [II.378]), just as the conclusion of a natural deduction proof can depend on assumptions. The fundamental truths on top of a complete grounding tree are individual propositions that do not express consequence relations themselves as the basic sequents which figure as logical axioms in Gentzen's sequent calculus do, and the conclusion depends upon them. Fundamental truths can figure as non-logical axioms in scientific theories, but they are not axioms in the logical sense. In a Bolzanian grounding tree the conclusion depends on the collection of fundamental truths on top: there is a dependence relation obtaining vertically. In a proof in Gentzen's

\footnotetext{
${ }^{50}$ This was also remarked by Buhl (1961), 86; Berg (1962), 164; Berg (1988), 22, Tatzel (2001), ch.4.3.

${ }^{51}$ Cf. Tatzel (2001), ch.4.1.

${ }^{52}$ Cf. Tatzel (2001), ch.4.3.

${ }^{53}$ In Bolzano's terms, a logical truth is a truth that is generally valid with respect to the collection of all non-logical ideas occurring in it, i.e., logical truths are truths that are true under any arbitrary variation of the non-logical ideas contained in them. Such logical truths can be logically deduced in the Bolzanian sense from any consistent collection of premises whatsoever. In the sequent calculus logical truths are proven by deriving a sequent of the form $\longrightarrow \phi$ from basic sequents of the form $\psi \longrightarrow \psi$. The meaning of those basic sequents is tautological in nature, and the endsequent does not depend upon them. Given Bolzano's constraints on the simplicity of the complete immediate ground of a conceptual truth, it is not clear what truths could possibly ground a logical truth, since 'such a proposition does not have the truth of its premises as a condition for its own truth'. Neither is it clear whether fundamental truths can be tautological in nature. Bolzano's simplicity constraints closely relate to his concept of exact deducibility (genaue Ableitbarkeit), and Bolzano explains that logical truths can figure neither as premises nor as conclusions in that relation (WL, §155.27 [II.124]).
} 
sequent calculus, on the other hand, the endsequent is based on logical axioms rather than on assumptions and expresses a dependence relation itself. It does not depend on the basic sequents from which it is derived. One might say that here the dependence relation obtains horizontally. In this line, a grounding tree of a conceptual truth $\phi$ based on a collection of fundamental truth $\Gamma$ would correspond to a cut-free derivation of the endsequent $\Gamma \longrightarrow \phi$ from basic sequents of the form $\psi \longrightarrow \psi$, where $\psi \in \Gamma$. The conclusion of a grounding tree depends on the fundamental truths on top, just as the succedent of the endsequent of a proof in the sequent calculus depends on the antecedent.

In both a cut-free proof in the sequent calculus and in a Bolzanian grounding tree, the conclusion is successively built up from its constituent parts. Bolzano's Complexity Constraint finds its analogue in Gentzen's Subformula Property. The structural differences between grounding trees and proofs in the sequent calculus that arise from the different treatment of assumptions, however, outrange the similarities between Bolzano's ideas on grounding and cut-free proofs in the sequent calculus. Since cut-free proofs in the sequent calculus vastly differ from Bolzano's grounding trees with respect to the treatment of assumptions and are moreover purely syntactical derivations, it seems more apt to compare grounding trees of conceptual truths to the normal natural deduction proofs considered by Dummett and Prawitz in the context of proof-theoretic semantics. In the calculus of natural deduction the dependence relation is established vertically, just as in a Bolzanian grounding tree, and the normal natural deduction proofs employed in proof-theoretic semantics are not understood as merely syntactical derivations, but are assigned a semantic interpretation.

\subsection{Grounding trees and normal proofs in proof-theoretic semantics}

\subsubsection{Normal natural deduction proofs and proof-theoretic semantics}

Proof-theoretic semantics is developed against the background of intuitionistic logic. When discussing normal proofs in natural deduction, I will therefore concentrate on the intuitionistic natural deduction calculus as presented in Prawitz (1965). This is by no means to say that I take Bolzano to be an intuitionist. All I want to claim is that there are certain similarities between the normal natural deduction proofs employed in proof-theoretic semantics and Bolzano's grounding trees of conceptual truths. ${ }^{54}$

Whereas Gentzen's sequent calculus constitutes an axiomatic calculus in which assumptions enter into the antecedents of the sequents, natural deduction derivations can depend on open assumptions. The inference rules of the calculus of natural deduction comprise an introduction and an elimination rule for each logical constant. Among those inference rules for the logical constants there are some which allow one to discharge certain assumptions on which the derivation depends. A derivation in which all open assumptions are discharged is called closed, otherwise open. Derivations are depicted in tree structures. Here again, the rules for conjunction are given as an example:

\footnotetext{
${ }^{54}$ Sticking to the intuitionistic background allows to draw parallels between Bolzano's grounding trees and normal natural deduction proofs in a perspicuous way, while a classical background would blur the result, since in classical logic only a restricted version of the Subformula Principle holds. What Bolzano was after are direct proofs and that is precisely what proof-theoretic semantics with its intuitionistic background provides.
} 
- Introduction rule: $\frac{A \quad B}{A \wedge B}$

- Elimination rule(s): $\frac{A \wedge B}{A}, \frac{A \wedge B}{B}$

The introduction rule for a logical constant allows one to infer a formula with that logical constant as its main connective from its immediate subformulas. An elimination rule is just the inverse of the corresponding introduction rule, as was remarked by Gentzen and is known as Prawitz's Inversion Principle. Gentzen writes:

To every logical symbol \&, $, \forall, \exists, \supset, \neg$, belongs precisely one inference figure which 'introduces' the symbol - as the terminal symbol of a formula - and one which 'eliminates' it. [...] The introduction rules represent, as it were, the 'definitions' of the symbols concerned, and the eliminations are no more, in final analysis, than the consequences of these definitions. (Gentzen (1935), 189 [Engl. 294 f.])

And Prawitz explains:

[A]n elimination rule is, in a sense, the inverse of the corresponding introduction rule: by an application of an elimination rule one essentially only restores what had already been established if the major premiss of the application was inferred by an application of an introduction rule. (Prawitz (1965), 33)

That is, nothing is gained if an elimination rule is applied to the conclusion of an application of the corresponding introduction rule. Introduction rules and elimination rules are 'in harmony', as Dummett calls it. ${ }^{55}$

From this it follows that a formula which is derived by the application of an introduction rule and at same time serves as major premise in an instance of the corresponding elimination rule constitutes a detour in a proof. Such detour forumulas are called maximum formulas (or in Dummett's terminology, 'local peaks' ${ }^{56}$ ). Prawitz's Normalization Theorem is the analogue of Gentzen's Hauptsatz. The Normalization Theorem shows that in a natural deduction derivation all maximum formulas can be eliminated by means of so-called reductions. ${ }^{57}$ In the case of conjunction, for example, a reduction amounts to the following:

$$
\frac{\frac{\Sigma_{1}}{A} \frac{\Sigma_{2}}{B}}{\frac{A \wedge B}{\frac{A}{\Pi_{3}}}} \stackrel{\text { reduces to }}{\longrightarrow} \frac{\frac{\Sigma_{1}}{A}}{\frac{\Pi_{3}}{\Pi_{3}}}
$$

If the conjunction is $A \wedge B$ derived by an introduction rule, the application of the corresponding elimination rule constitutes a detour. For, in order to derive the conjunction of $A \wedge B$ via an introduction rule, one must already be in possession of a derivation of $A$. A proof that contains no maximum formula is called normal. Prawitz explains:

\footnotetext{
${ }^{55}$ Dummett (1991), $247 \mathrm{f}$.

${ }^{56}$ Dummett (1991), $248 \mathrm{ff}$.

${ }^{57}$ Prawitz (1965), 34-50. The reductions in Prawitz correspond to the 'levelling of local peaks' in Dummett (1991), 248 ff.
} 
A deduction in normal form proceeds from the assumptions of the deduction to the conclusion in a direct and rather perspicuous way without detours; roughly speaking, the assumptions are first broken down into their parts by successive application of the elimination rules, and these parts are then combined to form the conclusion by successive application of the introduction rules. (Prawitz (1965), 8)

Each chain in a normal natural deduction proof can be divided into an elimination and an introduction part. ${ }^{58}$ Prawitz's so called Subformula Principle holds. The Subformula Principle states that every formula occurring in a normal proof is a subformula of either one of the premises or the conclusion. ${ }^{59}$

Proof-theoretic semantics is an alternative to model-theoretic semantics. ${ }^{60}$ In proof-theoretic semantics the meaning of a sentence is associated with its assertibility conditions in terms of a valid proof rather than with its truth conditions. A valid proof is thereby not understood as a merely syntactical derivation, but as representing a real argument that justifies the assertion of the sentence.

In proof-theoretic semantics in the tradition of Michael Dummett and Dag Prawitz the introduction rules of the calculus of natural deduction are taken to define the meaning of the logical constants, and proof-theoretic results on normalization are used to develop a semantics for proofs which is spelled out in terms of validity. The general idea is this: the application of an introduction rule as a meaning giving inference is 'self-justifying' ${ }^{61}$. That is, introduction steps are valid in virtue of the meaning of their respective conclusions. On the basis of the Inversion Principle, elimination steps can be justified by reductions. A proof is considered valid if all its elimination steps can be justified, i.e., if it can be reduced to a proof in which the conclusion is derived according to its meaning by the mere application of introduction rules.

The notion of validity is defined inductively. ${ }^{62}$ The definition basically rests on the proof-theoretic result that every closed normal proof has an instance of an introduction rule in the last step. ${ }^{63}$ Since introduction rules preserve validity, such a proof is considered valid if its immediate subproofs are. The validity of closed non-normal proofs and open proofs is defined in terms of their reducibility to valid closed normal proofs - after suitable substitutions of open assumptions by closed valid proofs for them have been carried out if necessary. In order to obtain an inductive definition of validity, an atomic base containing closed valid proofs for the atomic formulas (or in Dummett's terminology, a set of 'boundary rules' ${ }^{\prime 64}$ ) has to be provided. According to

\footnotetext{
${ }^{58}$ Note that Bolzano's grounding trees of conceptual truths do not contain a direct analogue to an elimination part. In the context of rigorous scientific representations of a science Bolzano demands, however, that all complex conceptual ideas occurring in one of the propositions of a grounding tree have to be accompanied by explanations which show from which simpler constituents they are built up (cf. WL, §378; Bolzano (1981), §§10, 11).

${ }^{59}$ Prawitz (1965), 42, 53.

${ }^{60}$ For an overview of proof-theoretic semantics, see Dummett (1991); Prawitz (1965), Prawitz (1974), Prawitz (2005), Prawitz (2006), Schroeder-Heister and Contu (2005), Schroeder-Heister (2006), Schroeder-Heister (2008), Schroeder-Heister (2013).

${ }^{61}$ Dummett (1991), $245 \mathrm{ff}$.

${ }^{62}$ For the definition of validity see Prawitz (1974), 71; Prawitz (2005), 688 f.; Prawitz (2006), 515; Dummett (1991), 252-261; Schroeder-Heister (2006), Schroeder-Heister (2013), ch.2.2.2.

${ }^{63}$ This is also known as Dummett's 'fundamental assumption' (Dummett (1991), 257).

${ }^{64}$ Dummett (1991), 255.
} 
the inductive definition of validity, a proof is valid with respect to an atomic base if by substituting open assumptions by closed valid proofs for them and by conducting reductions, it can be transformed into a proof in which the conclusion is derived by the mere application of introduction rules from (a subset of) its atomic subformulas, for which closed valid proofs are provided by the atomic base. Specifying an atomic base is the analogue to providing an interpretation of the non-logical vocabulary in modeltheoretic semantics. It determines the meaning of the atomic formulas. A proof can be valid with respect to an atomic base without its conclusion being generally valid. It is precisely the dependence on the atomic base that makes a valid proof represent a real argument. Logical validity amounts to validity with respect to any arbitrary atomic base, and only in this case must the conclusion be generally valid.

Without making any assumptions how the atomic base looks like, we cannot make precise statements about the form of a valid proof. In order to keep the present treatment as general and simple as possible, when concerned with valid proofs, we will simply consider them as being based on the atomic formulas themselves, thus ignoring the special character of the atomic base. It should, however, be kept in mind that the meaning of those atomic formulas depends on the atomic base.

A proof in which the conclusion is derived from (a subset of) its atomic subformulas by the mere application of introduction rules is by assumption valid, provided that closed valid proofs for the atomic formulas are supplied by the atomic base. Such a proof displays the meaning of its respective conclusion in terms of its assertibility conditions. It is those proofs that will be subject to the comparison with Bolzano's grounding trees, and we will refer to them in what follows as canonical normal proofs: ${ }^{65}$

We $[\ldots]$ define a 'canonical argument' to be one in which no initial premiss is a complex sentence [...] and in which all the transitions are in accordance either with one of the boundary rules [i.e. rules of the atomic base, AR] or with one of the given set of introduction rules. A canonical argument, as thus defined, is therefore by assumption valid, as expressed by Prawitz when he says that the introduction rules are 'valid by the very meaning of the logical constants'; in such an argument, all the initial premisses are atomic, and every complex sentence is derived by means of one of the given introduction rules. (Dummett (1991), 255)

\subsubsection{Comparison: grounding trees vs. canonical normal proofs}

Canonical normal proofs bear a strong resemblance to Bolzano's grounding trees of conceptual truths. As in the case with Gentzen's sequent calculus, the similarity arises first and foremost from the fact that canonical normal proofs proceed from the simple to the more complex, as required by Bolzano's Complexity Constraint. But let's have a closer look at the parallels between those two notions.

\footnotetext{
${ }^{65}$ I borrow Dummett's terminology from the passage quoted below in applying the term 'canonical' to proofs that are valid with respect to a given atomic base. Note that in proof-theoretic semantics a 'canonical proof' is typically said to be a proof that contains an application of an introduction rule in the last step (cf. Prawitz (2006), 512; Schroeder-Heister (2006), 536; Schroeder-Heister (2013), ch.2.2.2).
} 
Grounding trees and derivations in logical calculi First of all, it should be noted that there consists a very general difference between Bolzanian grounding trees on the one hand and derivations in logical calculi on the other. While derivations in logical calculi, such as the sequent calculus or the calculus of natural deduction, comprise formulas of a formal language, Bolzano's grounding trees consist of abstract, non-linguistic entities, viz., propositions. Bolzano's propositions differ from the formulas of a formal language not only with respect to their ontological status, but also with respect to their structure. Since Bolzano assumes that every proposition - even a complex one - has the underlying form ' $A$ has $b$ ', the subformulas of first order logic do not have direct counterparts in Bolzano. Bolzano does moreover not provide general rules as to how complex ideas can be built up from simpler ones. Regarding complexity, he can thus only refer to the simple content of his propositions.

A further difference between Bolzano's grounding trees and derivations in logical calculi in general consists in the fact that derivations in logical calculi are logically formal derivations, whereas grounding does not represent a formal relation at all. For the grounding relation, variation does not play a role in the first place. The formulas occurring in a derivation in some logical calculus, however, are uninterpreted formulas of a formal language, and given soundness, each step of a derivation is such that every interpretation of the non-logical vocabulary that makes the premises true makes the respective conclusion true as well. In Bolzano's system a logically formal consequence relation is provided by the notion of deducibility, in case all non-logical ideas occurring in one of the propositions involved are considered variable. As mentioned earlier, grounding is compatible with deducibility. With the concept of formal grounding (formale Abfolge) Bolzano provides a notion which is, roughly speaking, a simple blend of deducibility and grounding. He writes:

[...] I say that propositions $M, N, O, \ldots$ are formal consequences of [i.e. stand in a relation of formal grounding to, or are formally grounded in, $\mathrm{AR}$ ] propositions $A, B, C, \ldots$ with respect to ideas $i, j, \ldots$, if every collection of ideas whose substitution for $i, j, \ldots$ makes all of $A, B, C, \ldots$ true also makes all of $M, N, O, \ldots$ true, and if the truths generated from $M, N, O, \ldots$ are genuine consequences of the truths generated from $A, B$, $C, \ldots(\mathrm{WL}, \S 162[\mathrm{II} .193])^{66}$

In the case of formal grounding, the conclusion must be deducible from the premises with respect to a given collection of variable ideas, and whenever the variation results in a true variant of the premises, these must be such that they simultaneously ground the corresponding variant of the conclusions. Note that the premises of a formal grounding relation need not be true propositions themselves, whereas the plain grounding relation can hold only among truths. Bolzano moreover supposes that whenever a consequence is deducible from its ground, the grounding relation is a formal one, i.e., it is preserved under variation, although he has to admit that he does

\footnotetext{
${ }^{66}$ Ich sage also, daß die Sätze $M, N, O, \ldots$ zu den Sätzen $A, B, C, \ldots$ hinsichtlich auf die Vorstellungen $i, j, \ldots$ in dem Verhältnisse einer formalen Abfolge stehen oder aus ihnen formal abfolgen oder folgen, wenn jeder Inbegriff von Vorstellungen, der an der Stelle der $i, j$, die sämmtlichen $A, B, C, \ldots$ wahr macht, auch die sämmtlichen $M, N, O, \ldots$ in Wahrheiten und zwar solche verwandelt, die zu den Wahrheiten, $A, B, C, \ldots$ sich wie eine echte Folge zu ihrem Grunde verhalten.
} 
not have a proof for that claim (cf. WL, §200 [II.347]). Using our notation, we can restate Bolzano's definition of formal grounding as follows:

(FG) $\Gamma$ formally grounds $\Delta$ with respect to $v\left(\Gamma \Vdash_{v} \Delta\right)$ iff

(i) $\Gamma \vDash_{v} \Delta$; and

(ii) for all admissible $w$ : if $\Gamma(w / v)$ is true, then $\Gamma(w / v) \Vdash \Delta(w / v)$.

A logically formal grounding relation obtains if the collection of ideas which are considered variable comprises all non-logical ideas occurring in one of the propositions involved. If normal proofs - understood as purely syntactical derivations - represent grounding trees in the Bolzanian sense at all, then they represent logically formal ones. Bolzano provides the following example for a logically formal grounding rule, where the idea $[b+c]$ represents the property of having both $b$ and $c$ (WL, §199 [II.344], §227 [II.410 f.]):

$$
\frac{[A \text { has } b] \quad[A \text { has } c]}{[A \text { has } b+c]}
$$

Note that Bolzano's grounding trees contain propositions with a definite truth value, which therefore cannot contain variables, only variable ideas. In the linguistic representation of a formal grounding tree those variable ideas are indicated by variables (cf. WL, §223 [II.394]), just as in the grounding rule given above. The propositions themselves occurring in a grounding tree are, however, completely 'interpreted'.

It is important to note that unlike cut-free proofs in the sequent calculus, the canonical normal proofs employed in proof-theoretic semantics are not considered as merely syntactical derivations of uninterpreted formulas. Rather, they are understood as representing real arguments that justify the assertion of a sentence. The validity of a canonical normal proof depends on an atomic base, which fixes the meaning of the atomic formulas. In this sense, a proof that is valid with respect to an atomic base is on a par with a Bolzanian grounding tree, which contains propositions with a definite truth value. While proofs considered as merely syntactical derivations express logically formal relations, a proof whose validity depends on an atomic base strictly speaking does not. Logically formal relations such as captured in Bolzano's system in terms of variation of all non-logical ideas, only obtain if a proof is valid with respect to any arbitrary atomic base. What we consider in that case, however, is not a single proof, but rather several ones, each of which is supposed to represent a real argument. This is in line with Bolzano's requirement that logically formal grounding trees consist of propositions, which contain variable ideas, rather than variables.

Structural properties of grounding trees and canonical normal proofs As mentioned earlier, the structure of a derivation in the calculus of natural deduction differs from the structure of a derivation in the sequent calculus, which can be viewed as a meta-calculus of the calculus of natural deduction. In natural deduction, the conclusion is a single formula that depends on the assumptions of the derivation, whereas in the sequent calculus, the endsequent of a proof is derived from logical axioms, while the assumptions enter into the antecedents of the sequents. In this respect normal 
natural deduction proofs bear much more resemblance to Bolzano's grounding trees than Gentzen's cut-free proofs do. A complete grounding tree depends on the fundamental truths on top, just as a natural deduction proof can depend on assumptions. A natural deduction derivation of a formula from a set of assumptions takes the form of a tree with the assumptions at the top leaves and rooted in the conclusion. In the normal natural deduction proofs which are considered canonical in proof-theoretic semantics, the set of assumptions comprises atomic formulas only, and each step in the derivation consists in an instance of an application of an introduction rule. In a complete grounding tree, the conclusion depends on the fundamental truths on top, and each step in the tree consists in the relation between a complete ground and one of its immediate partial consequences. Complete grounding trees and canonical normal proofs follow the same buildup. Note that neither atomic formulas, nor fundamental truths can be proven by canonical means: an atomic formula cannot be derived by an introduction rule, and a fundamental truth cannot be further grounded. Nevertheless both can be proven: the atomic base provides closed valid proofs for the atomic formulas, and although fundamental truths cannot be proven by means of explanatory proofs, they can be proven via mere certifications, i.e. proofs based on the deducibility relation only (WL, $\S 487$ [IV.192]).

Not only do normal natural deduction proofs based on atomic assumptions nicely mirror the general buildup of complete grounding trees, but the introduction rules making up the steps of a canonical normal proof also share many of their relational properties with the immediate relation between a complete ground and one of its partial consequences, which holds in the individual steps of a grounding tree. Neither in the case of an instance of an introduction rule, nor in the case of immediate grounding can the conclusion itself be part of premises (cf. Irreflexivity $)_{\triangleright}$ ). In the maximal chains of both canonical normal proofs and complete grounding trees, each formula or proposition, respectively, can occur only once, although it can have multiple occurrences in the tree as a whole. The application of an introduction rule corresponds to an immediate step in the derivation, just as immediate grounding captures the direct relation between a complete ground and its immediate consequence (cf. Antitransitivity ${ }_{\Vdash}$ ). Moreover, a formula which serves as a premise in an instance of an introduction rule cannot be derived from the corresponding conclusion by means of some further application of that introduction rule. Both the immediate grounding relation and introduction rules mark one direction as canonical: they are one-way relations (cf. Asymmetry $\triangleright$ ).

One major difference between instances of immediate grounding on the one hand and introduction rules on the other, consists though in the fact that while the complete immediate ground of a given truth is always uniquely determined, according to Bolzano (cf. Uniqueness $\Vdash$ ), there might be more than one possibility for the premises of an instance of an introduction rule. The introduction rule for disjunction, for example, allows one to derive the disjunctive formula from either disjunct. Bolzano's simplicity requirement tells us to pick out the simplest one. However, this will not suffice to single out a unique one in general. Since there can be more than one possibility for the premises of an instance of an introduction rule, canonical normal proofs, unlike grounding trees, are not unique.

Uniqueness is a strong requirement, and the uniqueness assumption seems to be problematic in Bolzano's system itself. Next to the logically formal grounding rule that 
we considered above, Bolzano takes the following to be a logically formal grounding rule, where the idea $[A \cup D]$ represents the objects falling under at least one of the ideas $[A]$ or $[D]$ (WL, $\S 227$ [II.411 f.]):

$$
\frac{[A \text { has } b] \quad[D \text { has } b]}{[A \cup D \text { has } b]}
$$

Given those two logically formal grounding rules, there are two possible grounding trees for a proposition of the form ' $A \cup D$ has $b+c$ ':

$$
\frac{[A \text { has } b] \quad[A \text { has } c]}{\frac{[A \text { has } b+c]}{[A \cup D \text { has } b+c]} \frac{[D \text { has } b] \quad[D \text { has } c]}{[D \text { has } b+c]}}
$$

and

$$
\frac{[A \text { has } b] \quad[D \text { has } b]}{\frac{[A \cup D \text { has } b]}{[A \cup D \text { has } b+c]} \frac{[A \text { has } c] \quad[D \text { has } c]}{[A \cup D \text { has } c]}}
$$

Both trees are ultimately based on the same collection of propositions and meet the Complexity Constraint. They differ, however, with respect to the proposition figuring as the complete immediate ground of the required conclusion. Note that in a formal grounding relation the question which is 'the real complete immediate ground' of a proposition of the form ' $A \cup D$ has $b+c$ ' must not hinge on the particular character of the ideas substituted for the variables ones. Note also that in neither of those cases, the propositions making up the complete immediate ground of the conclusion contain any superfluous idea that is redundant for logically deducing that conclusion. Bolzano's requirements on the simplicity of the complete immediate ground are therefore of no help in choosing one of the trees over the other. This shows that a deducibility relation which fulfills both Bolzano's Complexity Constraint and his simplicity requirements cannot be sufficient for grounding (cf. section 3.5).

The similarity between Bolzano's grounding trees of conceptual truths and canonical normal proofs in proof-theoretic semantics arises first and foremost from the fact that the instances of introduction rules making up the steps of a canonical normal proof proceed from the simple to the more complex as required by Bolzano's Complexity Constraint. Each step of a grounding tree consists in the relation between a complete ground and one of its partial immediate consequences, and in case that consequence is a conceptual truth, none of the propositions figuring as part of its complete immediate ground must contain any occurrence of a simple idea that is not part of the consequence and they cannot contain more occurrences of one and the same simple idea than the consequence does. We expressed this by saying that the simple content of each partial ground must be a subcollection of the simple content of the immediate consequence. Analogously, the premises of an instance of an introduction rule only comprise formulas which are subformulas of the corresponding conclusion.

In a canonical normal proof as well as in a Bolzanian grounding tree of a conceptual truth, the conclusion is successively built up from its constituent parts: in a canonical normal proof, the conclusion is derived from its atomic subformulas by the mere application of introduction rules for the logical constants, while in a complete 
grounding tree it is built up step by step from its constituent simple ideas. In the maximal chains of both canonical normal proofs and complete grounding trees, one successively passes on to the more complex (or in Bolzano's case, as least as complex), starting out with atomic formulas or fundamental truths, respectively. As a consequence, every formula occurring in a canonical normal proof forms a subformula of the conclusion (Subformula Principle), just as every simple idea occurring in one of the propositions of a grounding tree must be a constituent part of the conclusion as well (Complexity Constraint). Neither canonical normal proofs nor grounding trees of conceptual truths contain any parts other than those occurring in their respective conclusions.

Note also that introduction rules satisfy Bolzano's constraints on the simplicity of the complete immediate ground. We have seen that Bolzano appears to require that in case of simultaneous deducibility the complete immediate ground should never contain any superfluous idea or proposition: all parts should be relevant for deducing the respective conclusion in a building-up fashion that is in line with the Complexity Constraint. Introduction rules meet this requirement. Every premise of an introduction rule is necessary for deriving the conclusion according to its meaning. A canonical normal proof, in which the conclusion is derived from (a subset of) its atomic subformulas by the mere application of introduction rules and which is supposed to display the meaning of its conclusion in terms of its assertibility conditions, does not make any detour, nor does it contain any formula or term that is redundant. Both in a grounding tree of a conceptual truth and in a canonical normal proof the conclusion is proven in a direct way without making use of anything that is superfluous for obtaining the conclusion in the relevant building-up fashion.

As mentioned earlier, since Bolzano takes it that every proposition - even a complex one - has the underlying form ' $A$ has $b$ ', but does not provide general rules as to how complex ideas can be built up from simpler ones, regarding complexity he can only refer to the simple content of his propositions. The recursive buildup of the formulas of a formal language, on the other hand, is thoroughly defined and gives rise to the notion of a subformula. It is of course possible to measure the complexity of a formula in terms of its atomic subformulas. ${ }^{67}$ In this line, we could define the atomic content of a formula as the collection of all occurrences of atomic formulas from which it is ultimately built up. We could then say that the atomic content of each formula figuring as a premise of an instance of an introduction rule forms a subcollection of the atomic content of the respective conclusion, just as the simple content of each proposition figuring as part of the complete immediate ground of a given truth forms a subcollection of the simple content of that truth.

Introduction rules as grounding rules Both complete grounding trees and normal proofs based on atomic assumptions are considered canonical proofs: grounding trees because they display the objective ground-consequence relations among true propositions, and normal proofs because they display the meaning of their respective conclusions in terms of their assertibility conditions. Neither grounding trees nor canonical normal proofs represent a purely extensional relation that can be explained in terms of truth preservation alone. We have seen that Bolzano's concept of deducibility, which is defined in terms of truth preservation, is not sufficient for grounding. And

\footnotetext{
${ }^{67}$ Cf. Tatzel (2001), ch.3.1.
} 
although the elimination rules of natural deduction are truth-preserving, just as the introduction rules are, in proof-theoretic semantics elimination steps need to be justified by reductions.

The premises of an instance of an introduction rule of natural deduction might very well serve as the objective ground of the corresponding conclusion, just as they are taken to define its meaning in proof-theoretic semantics. In this sense, the introduction rules of natural deduction might be regarded as grounding rules, or more specifically, as logically formal grounding rules. ${ }^{68}$ On the basis of the grounding rules considered above, it seems plausible to assume that Bolzano would agree that a conjunction is grounded in its conjuncts. ${ }^{69}$ Other rules are perhaps a little bit more problematic. We have, for instance, already seen that the introduction rules for disjunction do not meet Bolzano's requirement that the complete immediate ground of a proposition needs to be uniquely determined.

The introduction rule for implication in natural deduction exhibits a structure different from typical instances of grounding. If a formula $\phi$ is derivable from a formula $\psi$, the introduction rule for implication allows one to derive $\psi \rightarrow \phi$ and discharge the assumption $\psi$. Discharging assumptions is not possible in a Bolzanian grounding tree, which is supposed to reveal the objective ground-consequence relations among truth propositions. ${ }^{70}$ Note that in a canonical normal proof, which is taken to display the meaning of its respective conclusion, traces of discharged assumptions should not be neglected either. An analogue to the natural deduction introduction rule for implication would constitute a kind of meta-rule in Bolzano's system, allowing the introduction of a connective for mediate grounding. If $\psi$ is a supporting truth of $\phi$, we would be able to introduce $\psi \triangleright \triangleright \phi$ and discharge $\psi$. In the case of deducibility Bolzano actually admits a meta-rule which closely corresponds to the introduction rule for implication in natural deduction (cf. WL, §224 [II.397]).

Some further complication arises with respect to negation. Neither of the following derivation rules governing negation can constitute an instance of grounding.

\footnotetext{
${ }^{68}$ For a logic of grounding developed along Bolzano's lines, see Schnieder (2011).

${ }^{69}$ Cf. Centrone (2011), 13; Tatzel (2001), ch.1.2, where the introduction rules for conjunction are considered instances of grounding.

${ }^{70}$ The possibility to discharge assumptions introduces complexities into canonical normal proofs that are not present in Bolzano. A comparison with normal proofs in the natural deduction calculus in sequential format that Gentzen uses in his first inconsistency proof in 1936 might therefore be more apt (cf. Gentzen (1936), §5 f.). Next to basic sequents of the form $\phi \longrightarrow \phi$, this calculus also allows for basic sequents of the form $\longrightarrow \psi$, where $\psi$ is an arithmetical axiom. From those basic sequents the endsequent of a proof, which does itself not contain any antecedent formulas, is derived by the application of several structural rules and the introduction and elimination rules familiar from the calculus of natural deduction stated in sequential format. The basic sequents of the form $\longrightarrow \psi$ function as premises and cannot be discharged. While the calculus in question is surely advantageous in that it allows for the dependence on arithmetical axioms and thereby restricts validity, it crucially differs from Bolzano's grounding trees in that it introduces two kind of dependencies: next to the dependence on the arithmetical axioms, there is dependence on the antecedent formulas of a sequent, which is not to be found in Bolzano. Note that the normal proofs considered canonical in prooftheoretic semantics depend on an atomic base, which also restricts validity. General validity is only obtained if validity holds with respect to any arbitrary atomic base.
} 


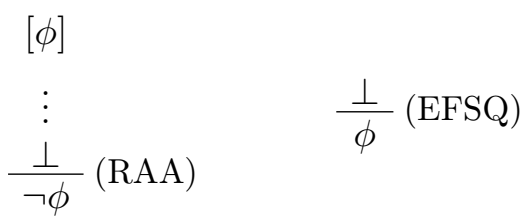

Bolzano has to deny that a proof by reductio ad absurdum constitutes an explanatory proof, since according to him, indirect proofs cannot be based on the grounding relation (WL, $\S 530$ [IV.271]). He explains that an indirect contains a detour and requires more premises than a direct proof of the conclusion does, which violates his requirement concerning the simplicity of the complete immediate ground. He further points out that an indirect proof obviously contains a false premise, while grounding can hold among true propositions only. ${ }^{71}$

The ex falso sequitur quodlibet cannot be an instance of the grounding relation either. Since the propositions that stand in a grounding relation need to be true propositions, the falsum is excluded as a possible ground. We have seen that the formal grounding relation is such that its relata can comprise false propositions as well. Yet, in a formal grounding relation the premises must be compatible with respect to the collection of variable ideas relative to which deducibility holds (cf. WL, $\S 155)$. In the logical case compatibility amounts to the modern notion of satisfiability. A contradiction, or the falsum, respectively, can never be satisfiable, and the ex falso sequitur quodlibet hence cannot constitute a formal grounding relation.

We have so far concentrated on the logical connectives of propositional logic. Let's finally have a look at what happens in the case of quantifiers. Quantified propositions in Bolzano exhibit a completely different structure than quantified first order formulas. In Bolzano every proposition that has more than one object falling under its subject idea amounts to a generally quantified proposition. It would be natural to assume that such propositions are grounded in their individual instances. For each object falling under the subject idea of a proposition there exists an idea in Bolzano's realm that represents precisely that object (cf WL, $\$ 101$ [I.470]). Yet, as there can be infinitely many objects falling under the subject idea of a proposition (cf. WL, §66), the number of instances of a universal proposition can be infinite. Sundholm (2011) therefore suggests to make use of the $\omega$-rule. ${ }^{72}$ However, such an approach gives rise to several problems in the realm of conceptual truths: first, if the complete immediate ground of a universal proposition could comprise infinitely many propositions, there would be horizontally infinite grounding trees of conceptual truths, which contradicts Bolzano's assumption that the number of supporting truths of a given conceptual proposition is finite (cf. WL, $\S 221$ [II.385 f.]). Second, the occurrences of simple ideas from which the subject idea of an instance of a universal proposition is built up need not all be part of the simple content of the universal proposition itself. Hence, considering the former a partial ground of the latter violates Bolzano's Complexity Constraint for conceptual truths. A similar case can be made in the case of the existential quantifier. In Bolzano an existential formula $\exists x F x$ translates into a proposition which states that there is at least one object falling under the idea $F$, viz., $[[F]$ has objectuality] (cf. WL, §137). Thus, each instance of an existential proposition contains at least some idea that is not part of the existential proposition itself, namely the subject

\footnotetext{
${ }^{71}$ For a discussion of indirect proofs in Bolzano, see Centrone (2012).

${ }^{72}$ Sundholm (2011), $57 \mathrm{f}$.
} 
idea of the instance, which again violates the Complexity Constraint for conceptual truths. While the individual instances of quantified first order formulas are considered subformulas of the formula in question, the simple content of an instance of a quantified proposition does not necessarily form a subcollection of the simple content of the quantified proposition. We could of course weaken the Complexity Constraint accordingly. Still there remains a certain tension between Bolzano's requirement of the finitude of the complete immediate ground of a conceptual truth on the one hand and the idea of grounding quantified propositions in their instances on the other. The problem might be related to Bolzano's general form of propositions ' $A$ has $b$ ' and his theory might be defective in that respect. In the case of universal propositions, adding the $\omega$-rule and consequently rejecting the idea that complete grounds are always finite collections would be one possibility to solve the issue. Another possibility, however, could be that Bolzano takes universal propositions to be grounded in other universal propositions rather than in their instances, which would nicely fit his requirement that the grounding relation ideally proceeds from general to more specific truths (cf. WL, $\S 221.6$ [II.387]).

\section{Conclusion}

We have seen that Bolzano's ideas on grounding, especially the ideas he develops in the context of conceptual truths, bear a strong resemblance to current notions of normal proofs. The similarity arises first and foremost from the fact that, just like grounding trees, normal proofs proceed from the simple to the more complex: Bolzano's Complexity Constraint finds its analogue in the subformula property of normal proofs. A major difference between grounding trees and normal proofs in general consists though in the fact that normal proofs unlike grounding trees are not unique.

I have moreover argued that the notion of a Bolzanian grounding tree is more adequately captured by the concept of a canonical normal proof as employed in prooftheoretic semantics than by a cut-free proof in Gentzen's sequent calculus. Canonical normal proofs are natural deduction proofs, and as such they exhibit the same structural buildup as grounding trees. The conclusion of a complete grounding tree depends on the fundamental truths on top, just as the conclusion of a canonical normal proof depends on the atomic subformulas from which it is derived and their respective meaning, which is provided by the atomic base. The endsequent of a normal proof in Gentzen's sequent calculus, in contrast, does not depend on the basic sequents from which it is derived. Those basic sequents function as logical axioms, while assumptions enter into the antecedents of the sequents: the sequents themselves express a dependence relation. These structural differences blur the similarities between Bolzano's grounding trees and cut-free proofs in the sequent calculus.

A very general difference between grounding trees and derivations in logical calculi arises from the fact that grounding is not a formal relation in the first place. If normal proofs, understood as purely syntactical derivation, represent grounding trees at all, they represent logically formal ones. Unlike cut-free proofs in the sequent calculus, canonical normal proofs are, however, not considered as merely syntactical derivations, but are assigned an interpretation in proof-theoretic semantics. Their dependence on the atomic base makes them represent real arguments that justify the assertion of a 
sentence. A canonical normal proof displays the meaning of its conclusion in terms of its assertibility conditions, while a grounding tree reveals the grounds of its conclusion.

Many of the properties that Bolzano ascribes to the relation between a nonfundamental truth and its complete immediate ground, which holds in the individual steps of a grounding tree, carry over to the instances of introduction rules, which make up the steps of a canonical normal proof. Yet, the question whether the introduction rules of natural deduction can be considered logically formal grounding rules is difficult to answer, given the fact that Bolzano's propositions exhibit a completely different structure than the formulas of a formal language. Bolzano was furthermore surely not only interested in the logically formal case of his grounding relation. A comparison with normal proofs nevertheless helps to shed some light on the general idea underlying Bolzano's concepts of grounding as a proof-theoretic notion.

\section{Acknowledgments}

This paper is based on my M.A. thesis 'Ableitbarkeit und Abfolge bei Bernard Bolzano vor dem Hintergrund des Modelltheoretischen und Beweistheoretischen Folgerungsbegriffs', Department of History and Philosophy, University of Tübingen, 2009, and I would like to thank Peter Schroeder-Heister for supervising my thesis. I am especially thankful to Stefan Roski for many long and fruitful discussions on Bolzano's paragraphs on grounding. I would moreover like to thank Arianna Betti, Michael De and Thomas Müller for comments on a previous version of this paper, the audience of the conference The Classical Model of Science II, Amsterdam, August 2011 and the members of the Bolzano reading group, Vrije Universiteit, Amsterdam. I acknowledge support by the Netherlands Organisation for Scientific Research, NWO VIDI 276-20-013.

\section{References}

Aristotle. Posterior Analytics. 2nd edition. Oxford: Oxford University Press. 1994.

Berg, J. (1962). Bolzano's Logic. Uppsala: Almqvist \& Wiksell.

Berg, J. (1988). Einleitung des Herausgebers. In: E. Winter, J. Berg, F. Kambartel, J. Louzil and B. van Rootselaar (eds.). Bernard Bolzano-Gesamtausgabe, I, 12/2. Stuttgart-Bad Cannstatt: Frommann-Holzboog. 9-22.

Betti, A. (2010). Explanation in Metaphysics and Bolzano's Theory of Ground and Consequence. Logique et Analyse, 211(53). 281-316.

Betti, A. (2012). Bolzano's Universe: Truth, Logic and Metaphysics. In: Haaparanta, L. and H.J. Koskinen (eds.). Categories of Being: Essays on Metaphysics and Logic. Oxford: Oxford University Press. 167-190.

Bolzano, B. (1837). Dr. B. Bolzanos Wissenschaftslehre: Versuch einer ausführlichen und größtentheils neuen Darstellung der Logik mit stetiger Rücksicht auf deren bisherige Beareiter. Bände 1-4. Sulzbach: Seidelsche Buchhandlung. English translation by Paul Rusnock and Rolf George. Unpublished. 
Bolzano, B. (1981). Von der Mathematischen Lehrart. J. Berg (ed.). Stuttgart: Friedrich Frommann-Holzboog. English translation: On the Mathematical Method. In: Rusnock, P. and R. George (eds.). (2004). On the Mathematical Method and Correspondence with Exner. Amsterdam/New York: Rodopi.

Buhl, G. (1961). Ableitbarkeit und Abfolge in der Wissenschaftslehre Bolzanos. In: Heidemann, I. (ed.). Kantstudien Ergänzungshefte, 83. Köln: Kölner Universitätsverlag.

Cellucci, C. (1992). Bolzano and Multiple-Conclusion Logic. In: Bolzano's Wissenschaftslehre 1837-198\%. International Workshop. Biblioteca di Storia della Scienza, 31. Florenz. 179-189.

Centrone, S. (2011). Begründungen bei Bolzano und beim frühen Husserl. Zeitschrift für philosophische Forschung, 65(1). 5-27.

Centrone, S. (2012). Das Problem der Apagogischen Beweise in Bolzanos Beyträgen und seiner Wissenschaftslehre. History and Philosophy of Logic, 33(2). 127-157.

Christian, C. (1974). Logische Wahrheit, Logische Folge und Abfolge im Bolzanoschen Sinn. In: Sitzungsberichte der Österreichischen Akademie der Wissenschaften. Philosophisch-Historische Klasse, 293, 5. Abhandlung. Bolzano Symposion: "Bolzano als Logiker". Wien. 46-62.

Correira, F. and B. Schnieder. (2012). Metaphysical Grounding: Understanding the Structure of Reality. Cambridge: Cambridge University Press.

Dummett, M. (1991). The Logical Basis of Metaphysics. London: Duckworth.

Fine, K. (2012). A Guide to Ground. In: Correira and Schnieder (2012). 37-80.

Gentzen, G. (1935). Untersuchungen über das Logische Schließen. Mathematische Zeitschrift, 39. 176-210, 405-431. English Translation: Investigations into Logical Deduction. American Philosophical Quarterly, 1(4): 1964. 288-306; 2(3): 1965. 204218.

Gentzen, G. (1936). Die Widerspruchsfreiheit der reinen Zahlentheorie. Mathematische Annalen, 112:1. 493-565.

Künne, W. (1997). Propositions in Bolzano and Frege. Grazer Philosophische Studien, 53. 203-240.

Lapointe, S. (2011). Bolzano's Theoretical Philosophy: An Introduction. Palgrave Macmillan.

Mancosu, P. (1999). Bolzano and Cournot on Mathematical Explanation. Revue d'Histoire des Sciences, 52. 429-455.

Morscher, E. (2013). Bernard Bolzano. In: Zalta, E.N. (ed.). The Stanford Encyclopedia of Philosophy. (Spring 2013 Edition). URL = $<$ http://plato.stanford.edu/archieves/spr2013/entries/bolzano/>. 
Prawitz, D. (1965). Natural Deduction: A Proof-Theoretical Study. Stockholm: Almqvist \& Wiksell.

Prawitz, D. (1974). On the Idea of a General Proof Theory. Synthese, 27. 63-77.

Prawitz, D. (2005). Logical Consequence from a Constructivist Point of View. In: Shapiro, S. (ed.) The Handbook of Philosophy of Mathematics and Logic. Oxford: Oxford University Press. 671-695.

Prawitz, D. (2006). Meaning Approached Via Proofs. Synthese, 148(3). 507-524.

Roski, S. and A. Rumberg. (2013). Simplicity and Economy in Bolzano's Theory of Grounding. Work in progress.

Rumberg, A. (2009). Ableitbarkeit und Abfolge bei Bernard Bolzano vor dem Hintergrund des Modelltheoretischen und Beweistheoretischen Folgerungsbegriffs. M.A. thesis. Department of History and Philosophy, University of Tübingen. Unpublished.

Rusnock, P. and M. Burke. (2010). Etchemendy and Bolzano on Logical Consequence. History and Philosophy of Logic, 31(1). 3-29.

Schnieder, B. (2011). A Logic for 'Because'. The Review of Symbolic Logic, 4. 444-465.

Schnieder. B. (2013). Bolzano on Causation and Grounding. Journal of the History of Philosophy. Forthcoming.

Scholz, H. (1937). Die Wissenschaftslehre Bolzano's. Eine Jahrhundert-Betrachtung. Abhandlungen der Fries'schen Schule. New Series, Volume 6. 399-472.

Schroeder-Heister, P. and P. Contu. (2005). Folgerung. In: Spohn, W., SchroederHeister, P. and E. Olsson (eds.). Logik in der Philosophie. Heidelberg: Synchron Wissenschaftsverlag. 247-276.

Schroeder-Heister, P. (2006). Validity Concepts in Proof-Theoretic Semantics. Synthese, 148(3). 525-571.

Schroeder-Heister, P. (2008). Proof-Theoretic versus Model-Theoretic Consequence. In: Pelis, M. (ed.). The Logica Yearbook 200\%. Prague: Filosofia. 187-200.

Schroeder-Heister, P. (2013). Proof-Theoretic Semantics. In: Zalta, E.N. (ed.). The Stanford Encyclopedia of Philosophy. (Spring 2013 Edition). $\mathrm{URL}=<\mathrm{http}: / /$ plato.stanford.edu.archieves/spr2013/entries/proof-theoretic se$\operatorname{mantics} />$.

Sebestik, J. (2012). Bolzano's Logic. In: Zalta, E.N. (ed.). The Stanford Encyclopedia of Philosophy. (Winter 2012 Edition). URL = $<$ http://plato.stanford.edu/archieves/win2012/entries/bolzano-logic/ $>$.

Shapiro, S. (2005). Logical Consequence, Proof Theory and Model Theory. In: Shapiro, S. (ed.). The Oxford Handbook of Philosophy of Mathematics and Logic. Oxford: Oxford University Press. 651-670. 
Siebel, M. (1996). Der Begriff der Abeitbarkeit bei Bolzano. Beiträge zur BolzanoForschung: Band 7. Sankt Augustin: Academia Verlag.

Siebel, M. (2002). Bolzano's Concept of Consequence. The Monist, 85(4). 581-601.

Sundholm, G. (2009). A Century of Judgement and Inference: 1837-1936. In: Haaparanta, L. (ed.) The Development of Modern Logic. Oxford: Oxford University Press. 263-317.

Sundholm, G. (2011). A Garden of Grounding Trees. In: Cellucci, C., Grosholz, E. and E. Ippoliti (eds.). Logic and Knowledge. Newcastle: Cambridge Scholars Publishing. 57-74.

Tarski, A. (1936). Über den Begriff der Logischen Folgerung. Actes du Congrés International du Philosophie Scientifique, 7. 1-11. English translation: On the Concept of Logical Consequence. In: Tarski (1956). 409-420.

Tarski, A. (1956). Logic, Semantics and Metamathematics. Oxford: Clarendon Press.

Tatzel, A. (2001). Proving and Grounding: Bolzano's Theory of Grounding and Gentzen's Normal Proofs. To appear in History and Philosophy of Logic.

Tatzel, A. (2002). Bolzano's Theory of Ground and Consequence. Notre Dame Journal of Formal Logic, 43(1). 1-25.

Tatzel, A. (2003). Bolzano on Grounding. In: Childers, T. and O. Majer (eds.). The Logica Yearbook 2002. Prague: Filosofia. 245-258. 